\title{
Experiment and Simulation Study on the Dynamic Response of RC Slab under Impact Loading
}

\author{
Yue Wang, ${ }^{1,2,3}$ Jun Liu $\mathbb{D}^{1,2,3}$ Zhimin Xiao, ${ }^{1,2,3}$ Futian Zhao, ${ }^{1,2,3}$ and Yi Cheng ${ }^{1,2,3}$ \\ ${ }^{1}$ College of Civil and Transportation Engineering, Hohai University, Nanjing 210098, China \\ ${ }^{2}$ Institute of Engineering Safety and Disaster Prevention, Hohai University, Nanjing 210098, China \\ ${ }^{3}$ Key Laboratory of Ministry of Education for Geomechanics and Embankment Engineering, Hohai University, \\ Nanjing 210098, China \\ Correspondence should be addressed to Jun Liu; ljun8@263.net
}

Received 12 September 2021; Accepted 10 November 2021; Published 28 November 2021

Academic Editor: Xuepeng Zhang

Copyright (C) 2021 Yue Wang et al. This is an open access article distributed under the Creative Commons Attribution License, which permits unrestricted use, distribution, and reproduction in any medium, provided the original work is properly cited.

\begin{abstract}
Reinforced concrete (RC) slab is an important component in civil construction and protection engineering, and its dynamic response under impact loading is a complex mechanical problem, especially for two or multiple continuous impact loads. In this paper, a series of drop hammer impact tests were carried out to investigate the dynamic response of RC slabs with two successive impacts. The time history of impact force and the failure characteristic of the slab surface were recorded. Moreover, four influence factors, including slab thickness, reinforcement ratio, impact location, and drop hammer height have been discussed. Besides, a 3D numerical model based on the finite element method (FEM) was established to expand the research of constrained force, deflection, and vertical stress of an RC slab. The results show that increasing the slab thickness and reinforcement ratio can improve the impact resistance of an RC slab. The impact point location and drop hammer height have a great influence on the dynamic response of the RC slab. In addition, the RC slab will have more obvious damage under the second impact, but the dynamic response becomes weaker. It may be because of the local damage in the concrete caused by the first impact that would weaken the propagation of vibration.
\end{abstract}

\section{Introduction}

In natural disasters, security incidents and military strikes, as one of the most important materials used in contemporary engineering structures, reinforced concrete (RC) components may be subjected to impact loads such as explosion and falling rock collision, resulting in bending failure, bending shear failure, and even brittle shear failure. The damage to some key RC components can cause instability or even collapse of the entire structure. The dynamic response of the RC components under the impact load is affected by impact energy, reinforcement ratio, component size, impact position, and other factors, which is a complex mechanical process. At present, the research methods of dynamic response of the RC components under the impact load mainly include theoretical method, experimental method, and numerical simulation method.
The elastic model is the earliest theoretical research model. Many scholars have conducted studies on the key parameters in the elastic model, such as peak stress-strain and ultimate stress-strain [1, 2]. Afifi [3] proposed the modified nonlinear elastic model under the monotonic or cyclic impact loading. Then, the plastic damage model was proposed, which combines the plastic theory with the damage theory to describe the constitutive equation of concrete dynamic failure and damage evolution, including HJC model, K\&C model, and RHT model [4]. In recent years, some scholars [5-7] have improved the above three models and applied them to the numerical calculation of shock and explosion. Besides this, Huo [8] proposed the concrete dynamic uniform viscoplastic model based on the energy dissipation theory. Rosa [9] put forward a time dependent cohesive model to account for the influence of loading rate on concrete fracture. Micallef [10] proposed an analytical model based on the critical shear crack theory, which can be 
applied to flat plates under impact loading. Because of the simplification of some factors, it is difficult to ensure the accuracy of the research results without accurately considering the boundary, environment, and other factors in reality.

Compared with the theoretical method, the experimental study is more intuitive and can provide a basis for theoretical analysis and numerical simulation. Bhatti [11] investigated the impact response of RC beams with sand cushions under falling loads. In the tests, $5000 \mathrm{~kg}$ weights were lifted by rail cranes to the specified heights of $2.5 \mathrm{~m}, 5 \mathrm{~m}, 7.5 \mathrm{~m}$, and $10 \mathrm{~m}$ and dropped freely to the middle of the span of the main beam. Özgür [12] carried out the drop hammer impact tests on eight reinforced concrete slabs to investigate the response of different boundary conditions on the reinforced concrete slabs under impact load. Kumar [13] designed a free-fall steel impactor test to investigate the impact force, acceleration, and deflection response of the prestressed and reinforced concrete slabs under impact loading. Li [14] conducted an explosion test to study the combined loading effect and failure characteristics of bidirectional RC slabs. Yao [15] analyzed the blast resistance and damage characteristics of reinforced concrete slabs with different reinforcement ratios by explosion experiments with $0.13 \mathrm{~kg}$ and $0.19 \mathrm{~kg}$ of TNT.

In addition, Wang [16], Sha [17], Soltani [18], Daneshvar [19], and Colombo [20] also studied the deformation and failure state of concrete components under impact load through experimental methods.

However, experimental methods have limitations and often require extended studies with the help of numerical simulation methods. With the continuous development of test technology and computer simulation, scholars have carried out a large number of numerical simulation studies on the dynamic response of $\mathrm{RC}$ members under impact loading. To study the influence of strain rate on the strength, stiffness, and ductility of RC beams, Ozbolt [21] simulated the three-dimensional RC beams with different shear reinforcement ratios and found that the developed rate-sensitive microplane model could well simulate the impact mechanical behavior of the RC beams. Lee [22, 23] used the finite element method (FEM) software to simulate the highspeed impact process of FRP-RC slab and steel fiber RC slab and found that FRP and steel fiber can reduce the impact dynamic response in the plate and enhance the impact resistance of the component. Zhao [24] established a 3D FEM model of the previous test, and the effects of impact velocity, impact mass, and span-depth ratio on the impact response of the RC beams were studied. The dynamic response and dynamic shear capacity of the RC beams were analyzed. The simulation research of Wang [25], Yan [26], Yankelevsky [27], and Castedo [28] on the dynamic response of the RC components also showed the superiority of the numerical simulation method in studying this problem.

Reinforced concrete slabs are widely used as the basic components in civil buildings and various engineering structures, such as building covers, fortifications, and retaining walls. However, the analysis of the dynamic performance of RC components in the existing studies concentrated mainly on components such as beams and columns, and a few studies alone on the RC slab discussed the dynamic response of the slab to the single impact. The dynamic behavior of the RC slabs is still an underrecognized area of research. In this paper, a series of drop hammer tests are conducted and four groups of FEM model for RC slabs are established using LS-DYNA to study the dynamic response of the RC slabs under two successive impacts. The effect of slab thickness, reinforcement ratio, impact location, and drop hammer height on the impact resistance of the RC slab is investigated.

\section{Experiment Setup}

To study the dynamic response of the RC slab under impact loading, a series of drop hammer impact tests were carried out. Each RC slab was continuously impacted twice by the drop hammer. The damage of the specimen surface after each impact and the time history curves of the impact force were recorded.

2.1. Design and Properties of Specimens. All test cases are shown in Figure 1, where the four variables (marked in blue) included in the study were slab thickness (group A), reinforcement ratio (group B), impact point location (group C), and initial height of the drop hammer (group D), with three cases in each group. The RC slab size in the test was $800 \mathrm{~mm} \times 800 \mathrm{~mm}$. In group $\mathrm{A}$, the thicknesses of A-1, A-2, and A-3 were $80 \mathrm{~mm}, 100 \mathrm{~mm}$, and $120 \mathrm{~mm}$, respectively. In group $\mathrm{B}$, the reinforcement ratio was changed by adjusting the diameter of the reinforcement, which were $0.22 \%, 0.32 \%$, and $0.4 \%$ in the three cases. For group C, the slabs used in these three cases have the same thickness and reinforcement ratio with $\mathrm{A}-2$, and these three kinds of impact location were "single reinforcement," "reinforcement intersection," and "concrete at the reinforcement mesh," respectively. The groups $D, \mathrm{D}-1, \mathrm{D}-2$, and D-3 represented the drop height of $1.5 \mathrm{~m}, 2 \mathrm{~m}$, and $2.5 \mathrm{~m}$, respectively, and the RC slab size and reinforcement were the same as B-1.

The concrete strength grade was $\mathrm{C} 25$, and the mix ratio was set as cement: sand: stone $:$ water $=1.0: 1.7: 3.15: 0.544$. All specimens were cured for 28 days in the same condition after pouring, while three concrete test cubes $(150 \mathrm{~mm} \times$ $150 \mathrm{~mm} \times 150 \mathrm{~mm}$ ) were prepared for the uniaxial compression test and the average compressive strength was $26.46 \mathrm{MPa}$. HPB300 steel bars with a diameter of $6 \mathrm{~mm}$ and $8 \mathrm{~mm}$ were used in the RC slabs, which had the yield strengths of $353.43 \mathrm{MPa}$ and $359.58 \mathrm{MPa}$, and the ultimate tensile strengths of $525.37 \mathrm{MPa}$ and $541.07 \mathrm{MPa}$, respectively. Each specimen had two layers of reinforcement mesh. The specimen is shown in Figure 2.

2.2. Testing Process. The drop hammer with a signal transducer was used to apply the impact load. The parameters of the drop hammer are shown in Table 1. The acquisition instrument was used to receive the drop hammer signal converted by the signal converter, and it was transmitted to the computer. Since RC slabs would not exist independently in practical engineering, a steel fixture was used to provide a constrained force for the RC slab. During the test, the tripod was expanded above the fixture to ensure that the projection of the fixed pulley coincided with the 

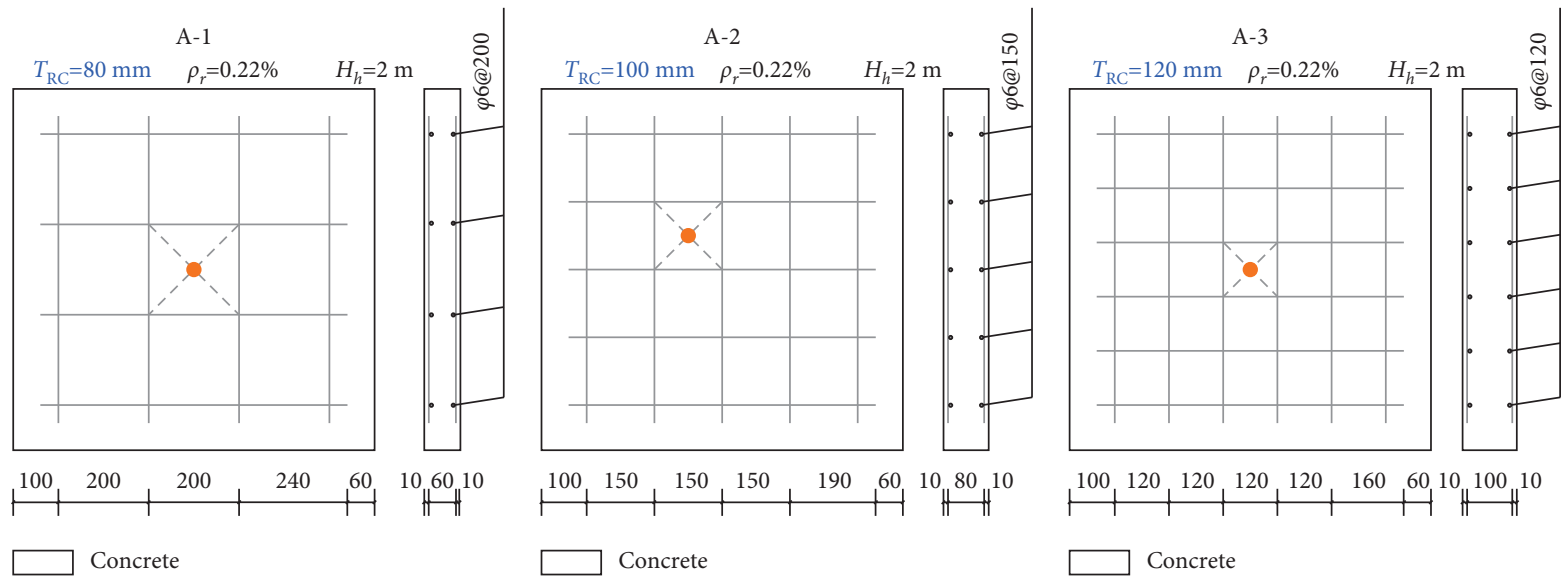

+ Rebar

+ Rebar

'o' Impact point

+ Rebar

-Impact point

(b)

(c)

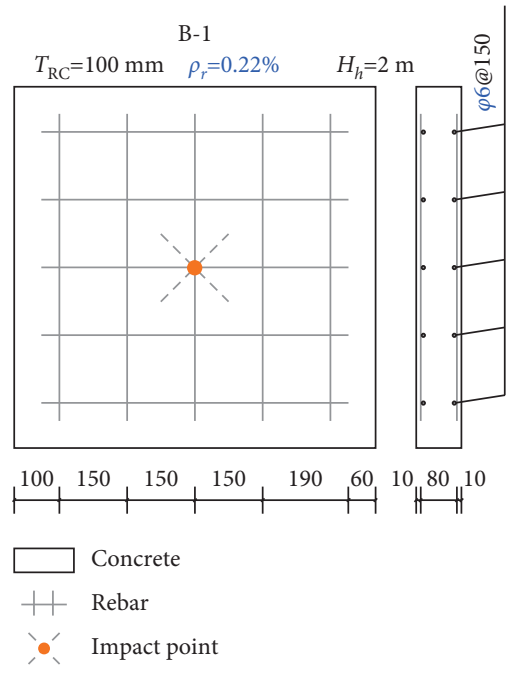

(d)

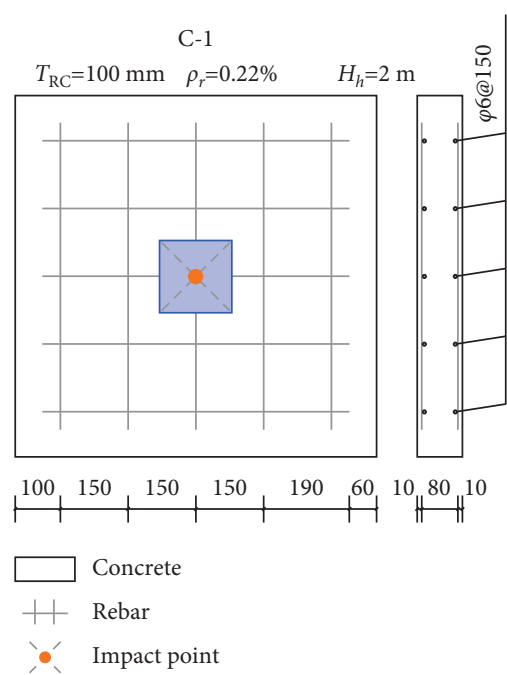

(g)

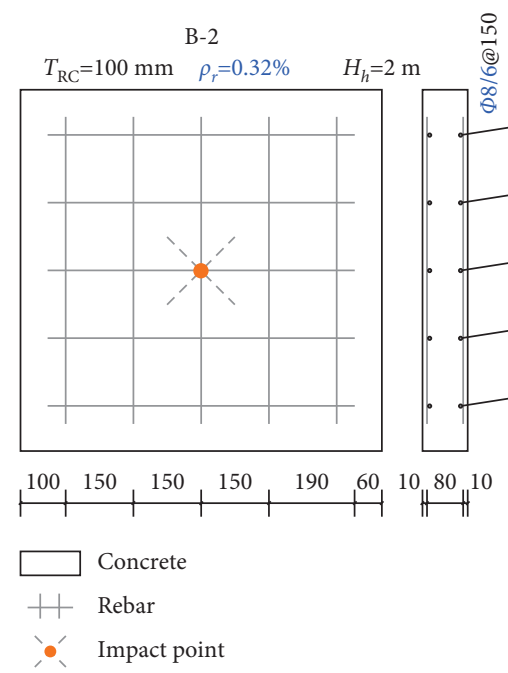

(e)

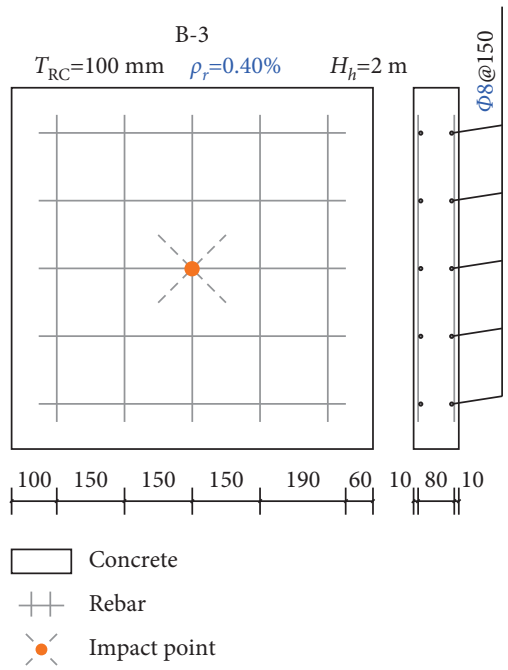

(f)

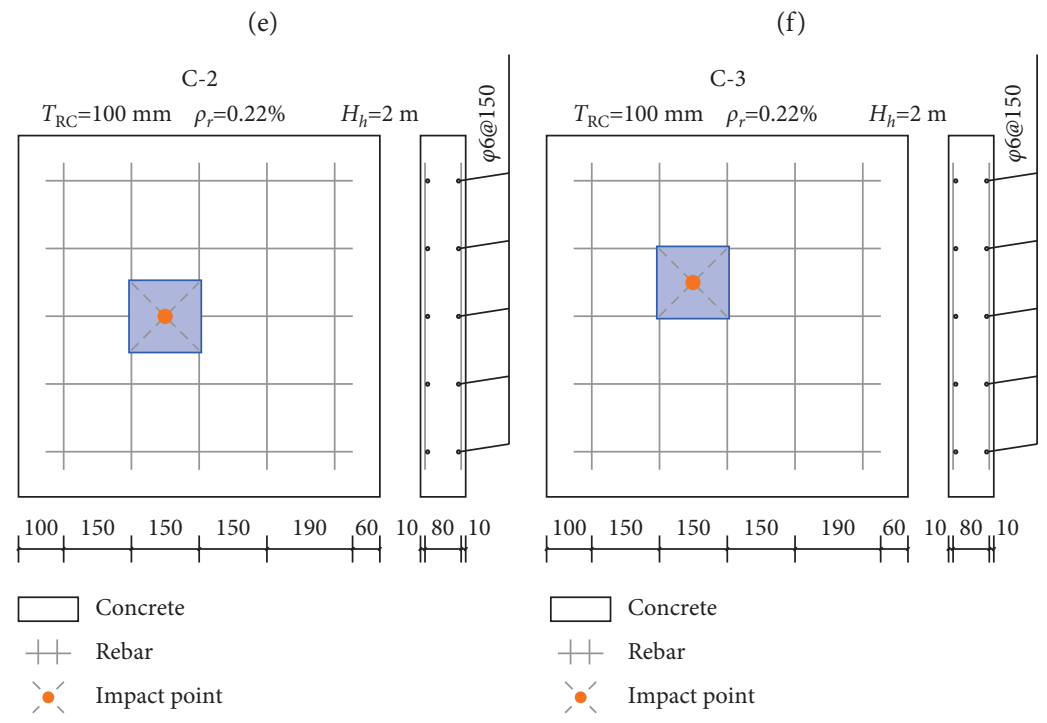

(h)

(i)

Figure 1: Design of specimens. (a) A-1. (b) A-2. (c) A-3. (d) B-1. (e) B-2. (f) B-3. (g) C-1. (h) C-2. (i) C-3. 


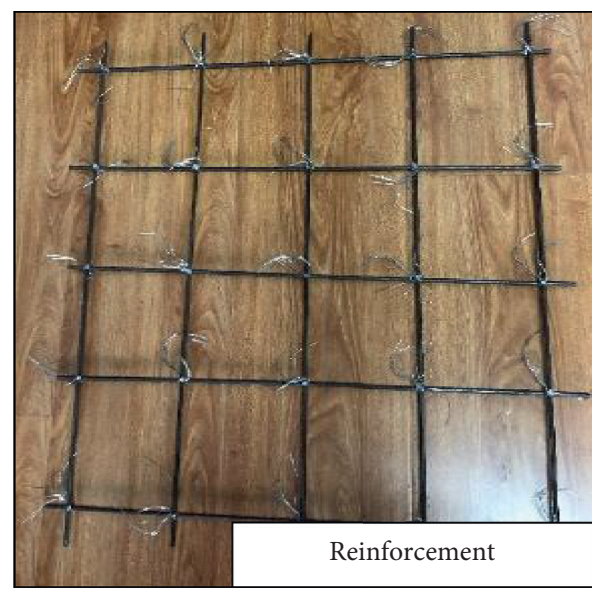

(a)

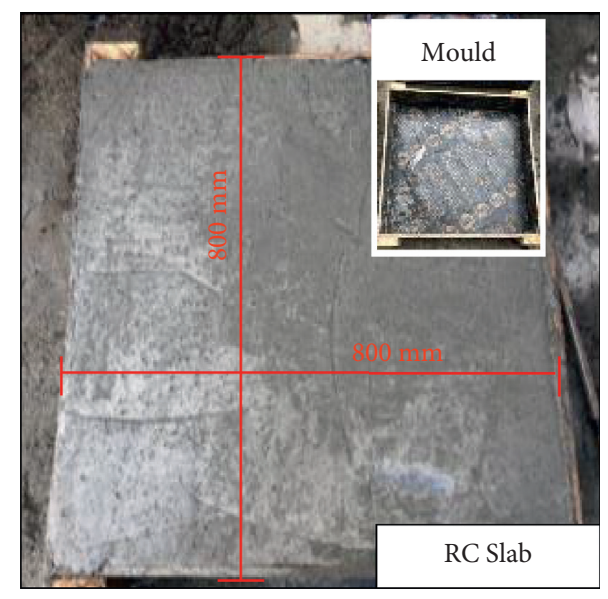

(b)

FIgURE 2: RC slab specimen.

TABLE 1: Specific parameters of the hammer.

\begin{tabular}{lccc}
\hline The mass of drop hammer $m(\mathrm{~kg})$ & Radius of hammer head $d(\mathrm{~mm})$ & Elastic modulus $E(\mathrm{GPa})$ & Density $\rho\left(\mathrm{kg} / \mathrm{m}^{3}\right)$ \\
\hline 11.1 & 47.5 & 200 & 8300 \\
\hline
\end{tabular}

designed impact point of the RC slab. The force transducer on the drop hammer was connected to the signal converter, the other end of the signal converter was connected to the acquisition instrument, and the acquisition instrument was linked to the computer to form a monitoring system. The drop hammer was lifted to the design height by a rope, and it fell freely and impacted the RC slab. After that, the hammer was reset, the time history curve of the impact force generated by the first impact and the damage state of the specimen were recorded, and the above operations were repeated for the second impact. The instrument arrangement of the whole testing system is shown in Figure 3.

\section{Numerical Simulation}

Because of the limitation of the test conditions, a FEM model was established to further study the dynamic mechanical properties of the RC slab using LS-DYNA, and all simulated cases were under the same conditions as the aforementioned drop hammer tests. Firstly, the rationality of the numerical model was verified by comparing the test and simulation result of the impact force time history curve. Then, the constrained force, deflection of RC slab, and vertical stress were investigated.

3.1. Establishment of FEM Model. The finite element model consisted of four parts: drop hammer, concrete, steel reinforcement, and fixture. In this model, the SOLID164 entity element was selected for concrete, which is usually used for a three-dimensional explicit dynamic solution under nonlinear and large deformation conditions. The CSCM model (MAT_159) was used for a constitutive model of concrete. Many scholars' studies $[29,30]$ show that the CSCM model can well simulate the bending and shear behavior of the RC structures under one or more shocks, especially in the case of low-velocity impact. The CSCM model can simulate the strain softening and stiffness degradation of concrete after reaching its peak strength under impact load by considering the hardening, damage, and rate correlation of the concrete materials. The reinforcement adopted the BEAM161 entity element, and its constitutive model was a plastic kinematic model (*MAT_PLASTIC_KINEMATIC). The drop hammer was simplified as a spherical cylinder composed of a cylinder and a hemisphere. The diameter of the cylinder was $95 \mathrm{~mm}$, the height was $150 \mathrm{~mm}$, and the diameter of the hemisphere was the same as that of the cylinder. The SOLID164 entity element was also selected for the drop hammer and fixture. Since the drop hammer and fixture had almost no deformation in the test, both of them adopted a relatively simple rigid material model ( $*$ MAT_RIGID) as the constitutive model. The previous researches show that with the increase of the loading rate, the bond performance of the steel reinforcement in concrete gradually increases $[31,32]$. Hence, the steel reinforcement and concrete in the numerical model were coupled by the common node method. The FEM model is shown in Figure 4.

3.2. Setting of Contact Mode and Constraint Condition. A total of four contacts were defined in the FEM model: drop hammer-concrete, drop hammer-steel reinforcement, steel reinforcement-concrete, and concrete-fixture, all of which used the face-to-face contact mode because of the large contact area between the objects. The keyword *CONTACT_ERODING_SURFACE_TO_SURFACE was employed for the contact mode, where the static friction coefficient of the contact surface was set as 0.2 and the dynamic friction coefficient was set as 0.1 . 


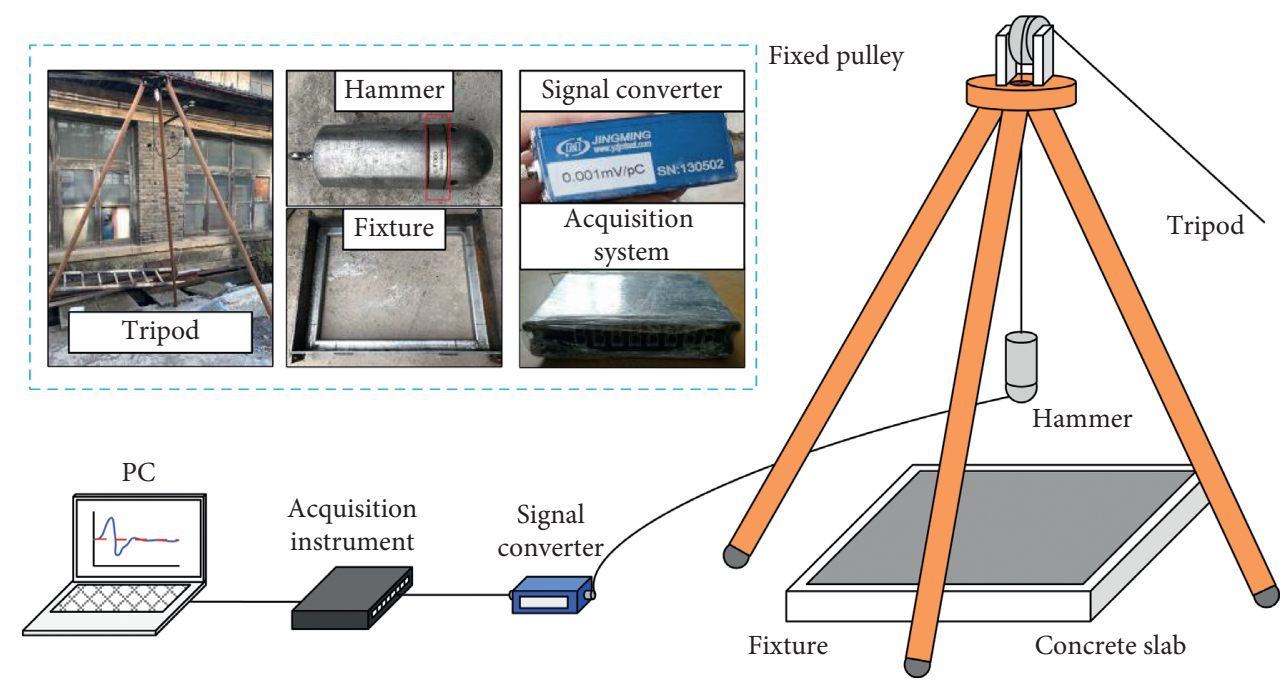

Figure 3: The instrument arrangement of the test system.

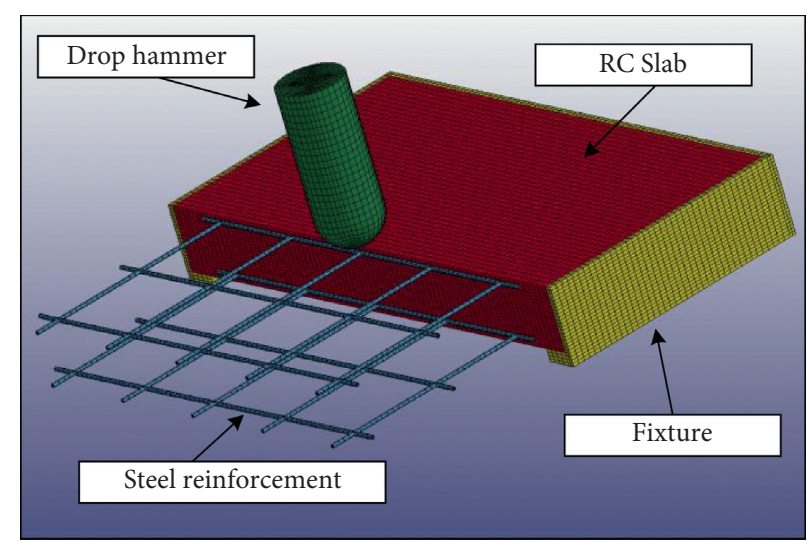

FIgURE 4: FEM model of drop hammer test.

The parameters of the hammer and fixture were set as shown in Table 2. MID, COUPLE, $M$, N, CMO represent the material number, coupling mode, and constraint options, respectively. For the drop hammer, setting "CON1" as 4 in the material parameter means that the drop hammer can only produce translation in the $Z$ direction (impact direction) while limiting rotation in the $X, Y$, and $Z$ directions and translation in the $X$ and $Y$ directions. For the fixture, setting "CON1" as 7 means that the fixture cannot produce translation and rotation in all three directions. For the RC slab, the no-reflection boundary constraint was applied around it.

3.3. Applying of Impact Load. In the whole impact process, the energy and mass loss of the drop hammer were ignored so that its gravitational potential energy was purely converted into kinetic energy, and it is easy to know that the impact velocity of the drop hammer reaching the RC slab was $V_{0}=\sqrt{2 g H}$. The drop hammer was established $1 \mathrm{~mm}$ above the RC slab to reduce the solution time. The keyword * INITIAL_VELOCITY_GENERATION was employed for defining the initial velocity of the drop hammer impact.
Since the test only contained three initial hammer heights of $1.5 \mathrm{~m}, 2 \mathrm{~m}$, and $2.5 \mathrm{~m}$, the keyword set three kinds of impact velocity of $5.42 \mathrm{~m} / \mathrm{s}, 6.26 \mathrm{~m} / \mathrm{s}$, and $7 \mathrm{~m} / \mathrm{s}$, respectively. For applying the secondary impact load, the solution procedure could be suspended after the drop hammer completed a single impact, and the drop hammer speed could be modified and applied by a restart in LS-DYNA.

\subsection{Comparison of Numerical Calculation and Test Result.} The previous studies show that the impact force can reflect the mechanical properties of two collision objects $[33,34]$. For example, according to Hertz contact theory, the magnitude of the impact force is related to the impact velocity, the mass, size, Young's elastic modulus, and Poisson's ratio of the two collision objects.

Therefore, the feasibility of the numerical simulation model was verified by comparing the experimental value and simulation value of the drop hammer impact force. The impact force time history curves of group B and group $D$ were used for analysis, which are shown in Figure 5. It can be seen from the figure that the simulation value is close to the experimental value. For example, when the three kinds of 
TABLE 2: FEM model parameters of hammer and fixture.

\begin{tabular}{lcccccc}
\hline Part & Mid & Couple & M & N & Cmo & Con1 \\
\hline Hammer & 3 & 0 & 0 & 0 & 1 & 4 \\
Fixture & 4 & 0 & 0 & 0 & 1 & 7 \\
\hline
\end{tabular}
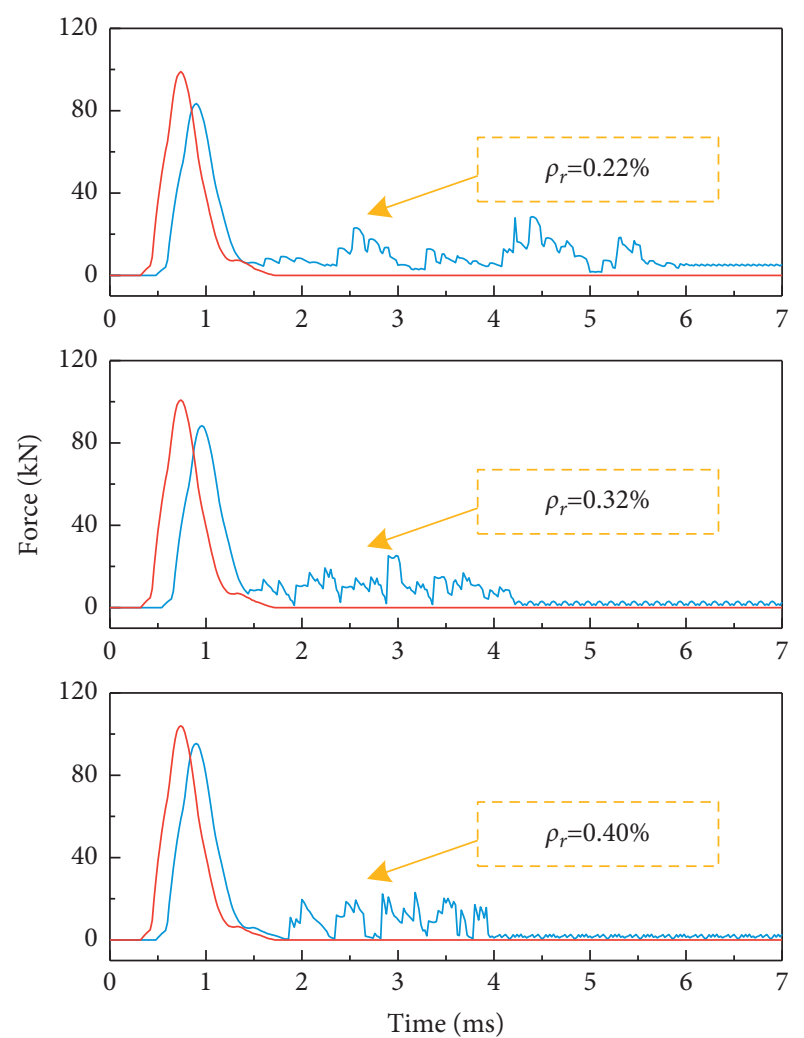

Test result
_ Simulation result

(a)
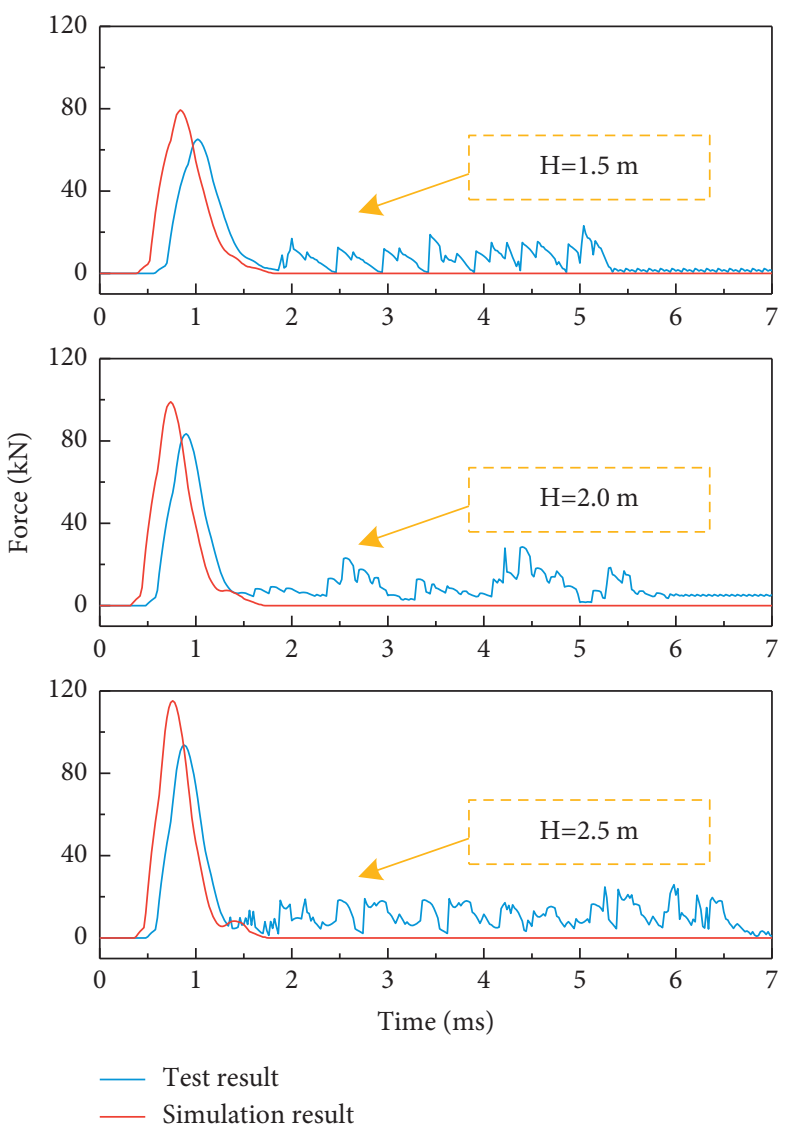

(b)

FIgURE 5: Comparison of impact force time history.

initial height of the falling hammer are $1.5 \mathrm{~m}, 2.0 \mathrm{~m}$, and $2.5 \mathrm{~m}$, the peak impact force of the numerical simulation are $79.4 \mathrm{kN}, 98.9 \mathrm{kN}$, and $111.7 \mathrm{kN}$, which are similar to the peaks obtained from the tests $(65.2 \mathrm{kN}, 83.5 \mathrm{kN}$, and $93.7 \mathrm{kN}$ ). From the main part of the curve, the shape of the test and simulated value are almost the same. Some differences between the test and simulation results can also be found. In all cases, the impact force simulation curve goes to zero directly after the impulse load is generated, but the test curve produces a series of fluctuations. On the one hand, this may be because of the limitation of the concrete material model selected in LS-DYNA, which caused the falling hammer to be bounced off in the opposite direction after impact, and on the other hand, it may be because of the fact that the gravity effect was not considered during the FEM analysis. Overall, the impact force simulation curves are close to the test curves in the numerical size and change rule, so it is feasible to use the numerical model to study the dynamic response of the RC slabs under impact loading.

\section{Results and Discussion}

4.1. Surface Damage of RC Slabs. Figure 6 shows the damage of the specimen surface under two continuous impact loads. After the application of the second impact, the cracks on the surface produced by the first impact extended toward the boundary of the slab while new cracks were produced. As the slab thickness increases, the number of cracks gradually reduced, and the crack propagation is weakened, indicating that the damage of the specimen decreases and the impact resistance improves. When the reinforcement ratio of the RC slab was changed, the crack distribution and damage state of the three specimens did not differ much. For group $\mathrm{C}$, the number of cracks was the least when the impact position was above the single row of steel reinforcement. The other two cases produced the same number of cracks, but the length of the cracks was longer when the impact location was located on the concrete at the reinforcement mesh, which indicates that the dynamic response of the RC slab was more 


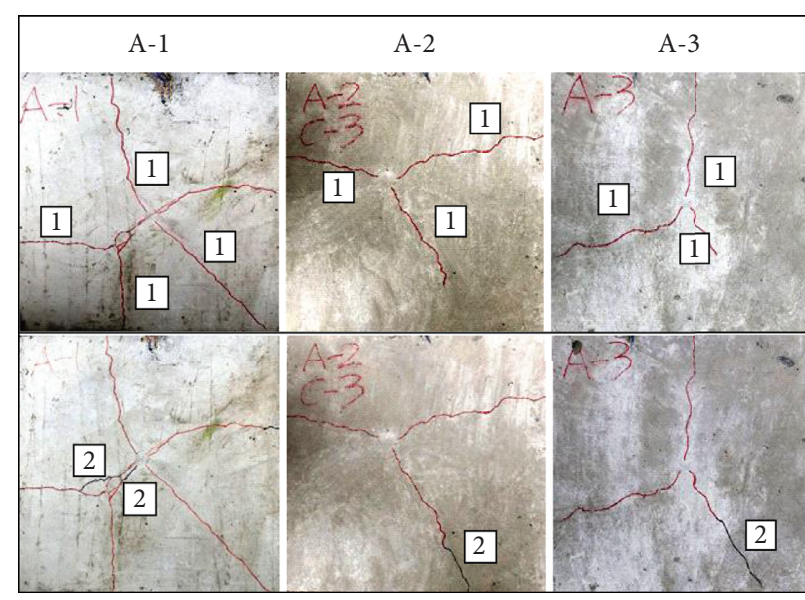

(a)

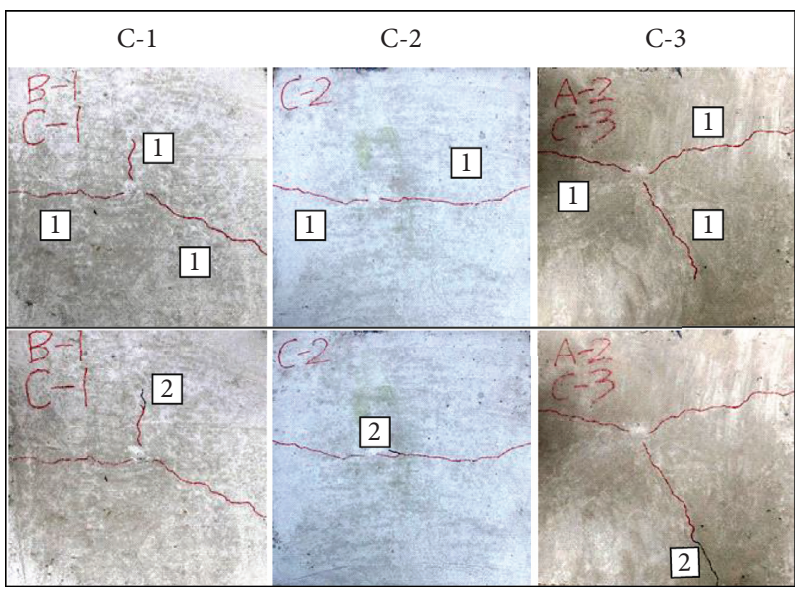

(c)

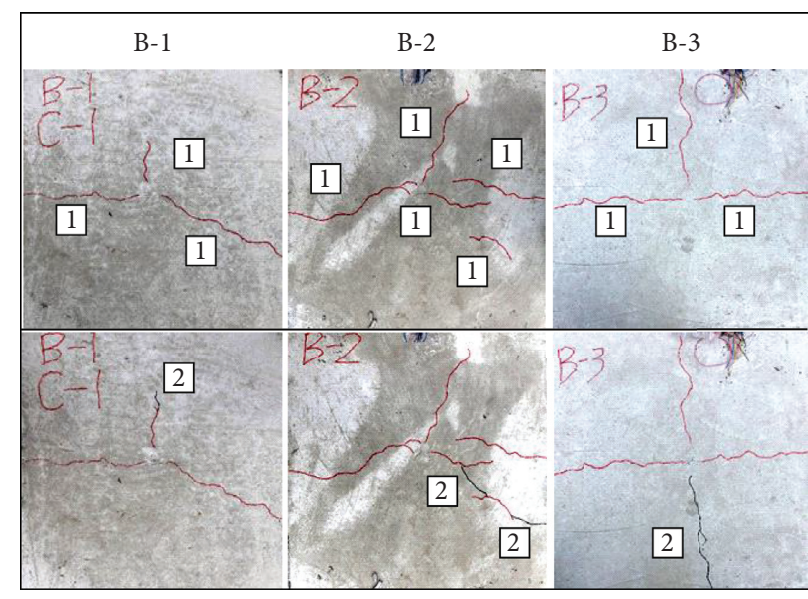

(b)

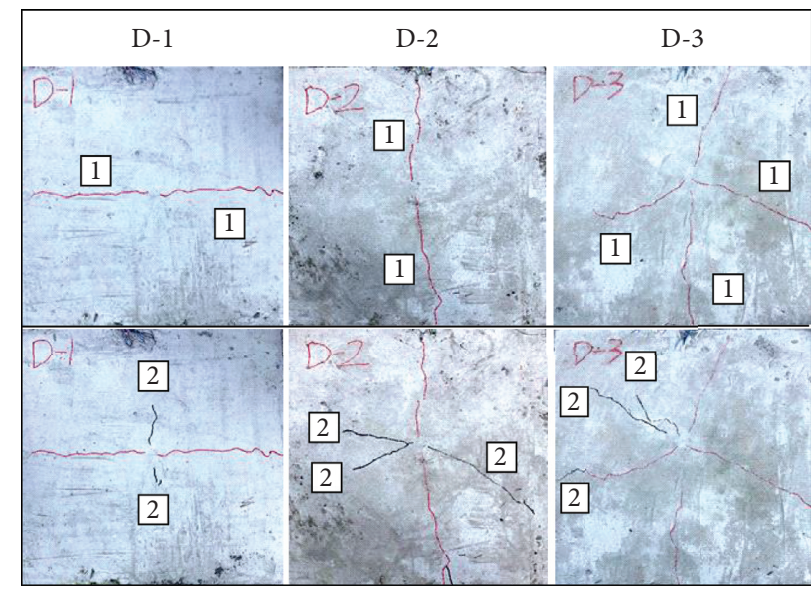

(d)

Figure 6: Surface damage of specimens.

intense in this case. With the increase of the initial height of the falling hammer, the number of cracks in the specimen increased significantly, indicating that the damage of the specimen was gradually severe with the increase of the impact energy.

4.2. Time History of Impact Force. Figure 7 shows the time history curves of the impact force for the four groups of specimens. From the results of the first impact, it is found that with the increase of the slab thickness, the peak impact force of the specimen increases, where the peak impact force of A-3 is approximately $40 \mathrm{kN}$ higher than that of A-1. For group $\mathrm{B}$, increasing the reinforcement ratio does not affect the peak impact force magnitude, and the dynamic response of the RC slab is relatively similar throughout the impact process. The impact point of C-3 during the test was not the geometric center of symmetry of the specimen, which was closer to one side of the fixture, resulting in a more violent local response, and hence, the peak impact force is the largest. In group $D$, with the increase of the drop height, the peak impact force increases and the impact force duration gets longer. This may be because of the plastic damage in addition to the elastic deformation in the slab, which resulted in the broken concrete and hammer head to continue to act to increase the response time. The higher the drop height, the more the concrete was broken and the stronger the response occurred. Compared with the first impact, the peak impact force of the second impact is reduced by approximately $10-20 \mathrm{kN}$, indicating that the stiffness of the specimens has decreased.

4.3. Constrained Force of RC Slab Boundary. The constrained force of the RC slab boundary can reflect the force situation of the supporting or restraining components of the slab such as column in actual engineering. Figure 8 shows the time history curves of the constrained force subjected to the first impact for the four groups of simulation. Similar to the drop hammer impact, the constrained force of the RC slab is also in the form of a short pulse.

For group A, the peak constrained forces are $11.7 \mathrm{kN}$, $16.0 \mathrm{kN}$, and $21.8 \mathrm{kN}$, which indicates that the force between the RC slab and fixture increases gradually with the increase of slab thickness under the same impact energy. This may be because of the increase of slab thickness resulting in an increase in the contact area between the slab and the four sides of the fixture, resulting in an increase in the self- 


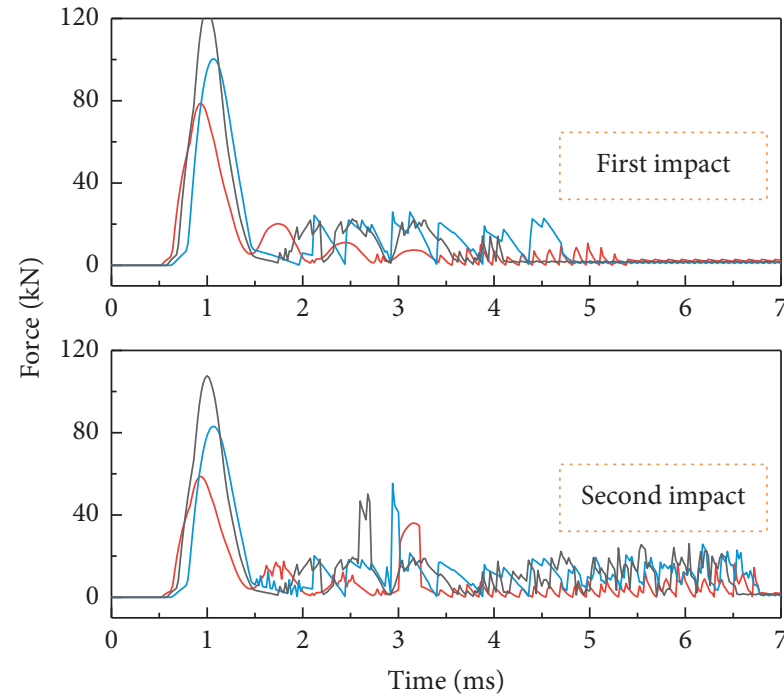

- A-1

- A-2

- A-3

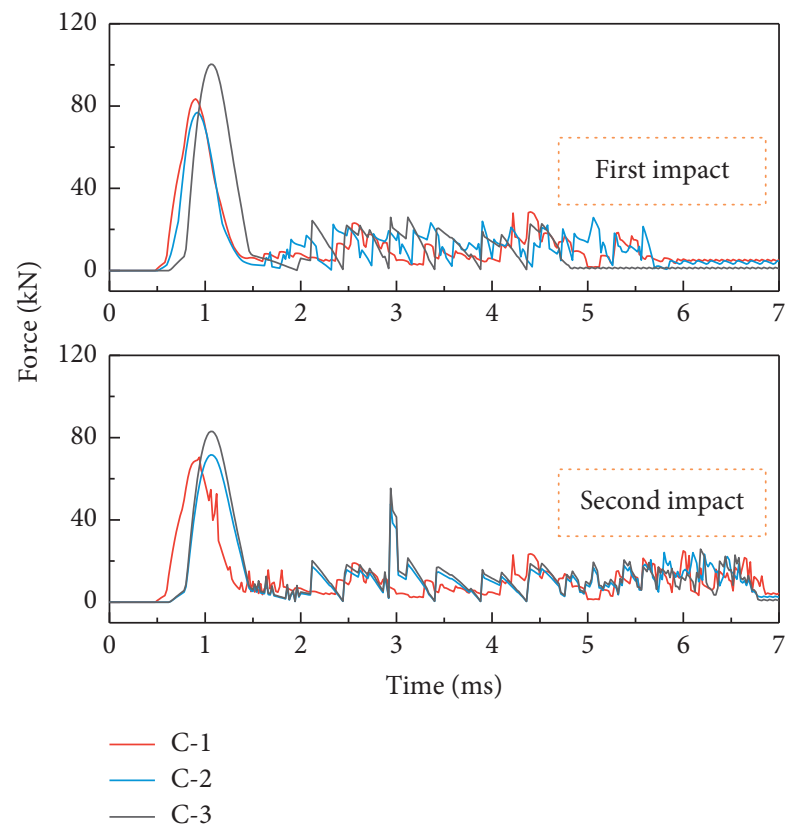

(c)

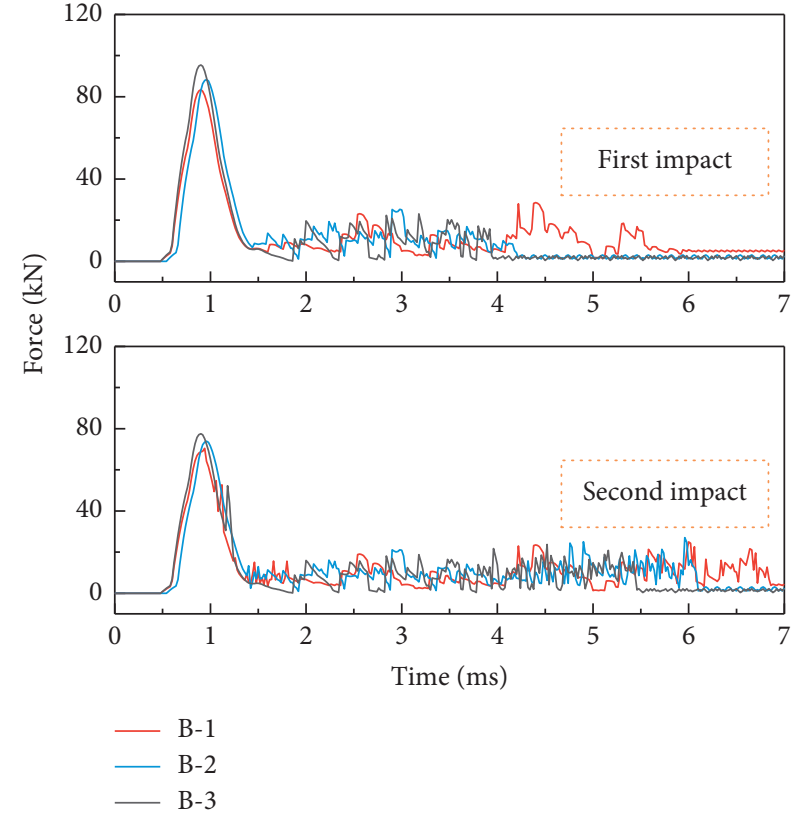

(b)

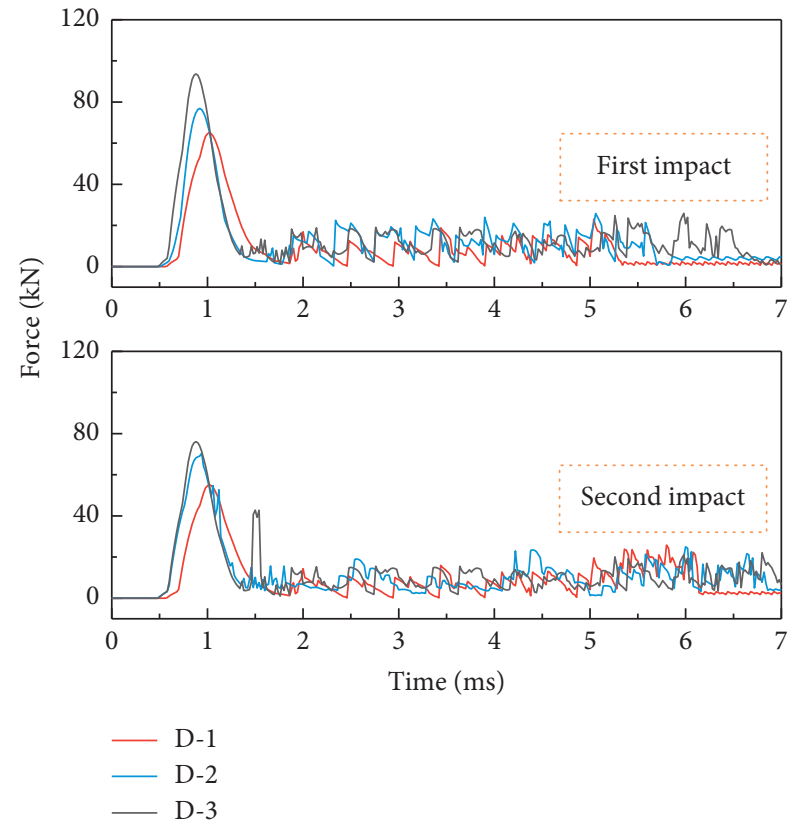

(d)

FIgURE 7: Time history curves of impact force.

binding force of the thicker slab specimen. In group $\mathrm{B}$, the peak constrained forces are $13.3 \mathrm{kN}, 15.2 \mathrm{kN}$, and $16.1 \mathrm{kN}$, respectively. With the increase of reinforcement ratio, the constrained force of the RC slab boundary was not significantly affected, indicating that the main factor affecting the magnitude of the constrained force under the same impact energy is the concrete that directly came in contact with the fixture. The constrained force of C-3 $(16.0 \mathrm{kN})$ is higher than that of C-1 $(13.3 \mathrm{kN})$ and $\mathrm{C}-2(12.5 \mathrm{kN})$, indicating that the strongest dynamic response was generated when impacting the concrete located at the steel reinforcement mesh. In group $D$, the peak constrained force increases with the increase of drop hammer height, and the dynamic response of RC slab is enhanced.

4.4. Deflection of RC Slab Center. Figure 9 shows the deflection time history curves of the RC slab center under the first impact load. All RC slabs produce a peak deflection after impact, of which the value is $1.2 \mathrm{~mm} \sim 2 \mathrm{~mm}$, and they undergo periodic vibrations. The minimum value of the deflection periodic variation is regarded as the 


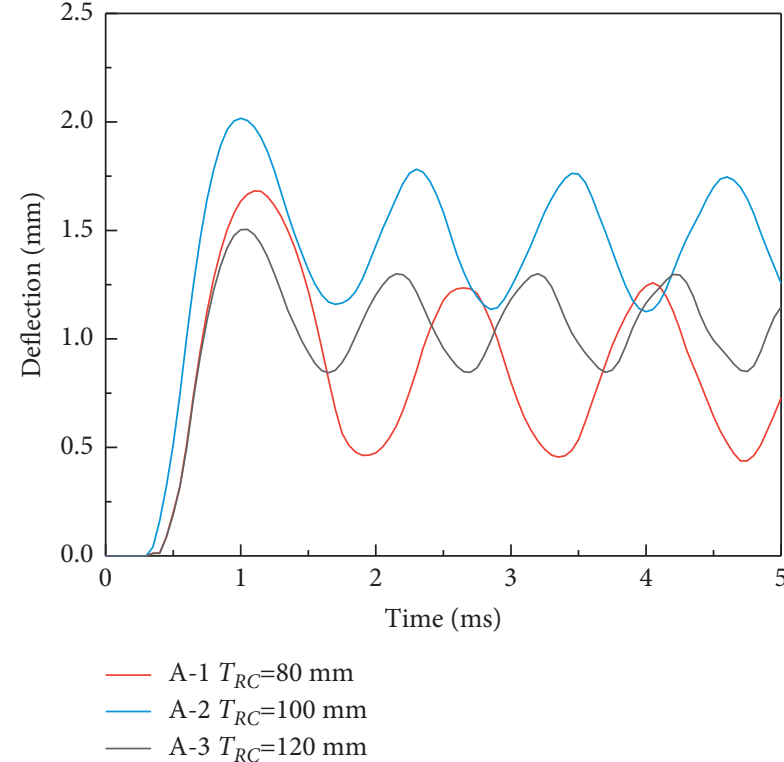

(a)

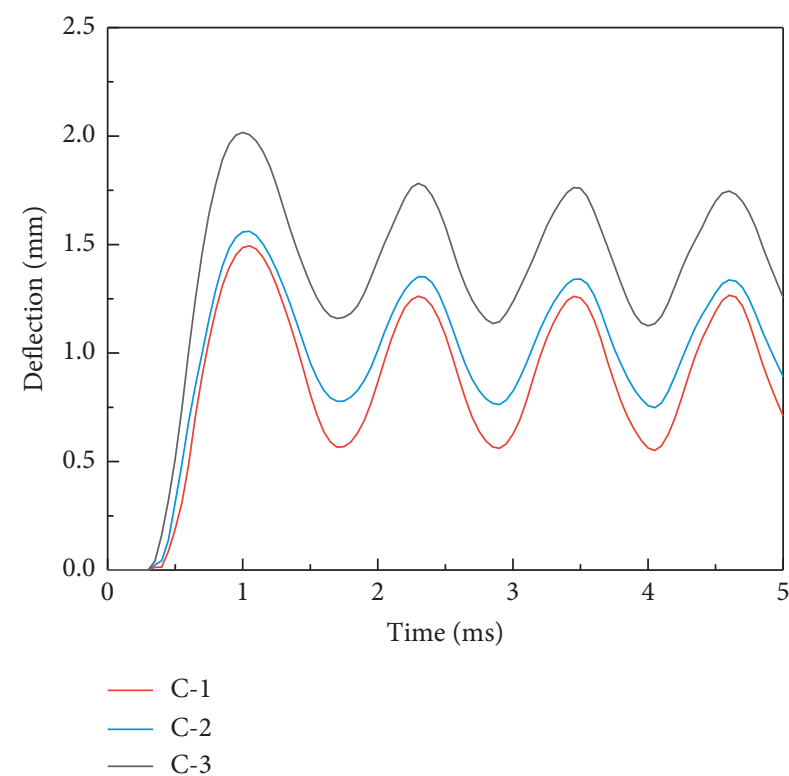

(c)

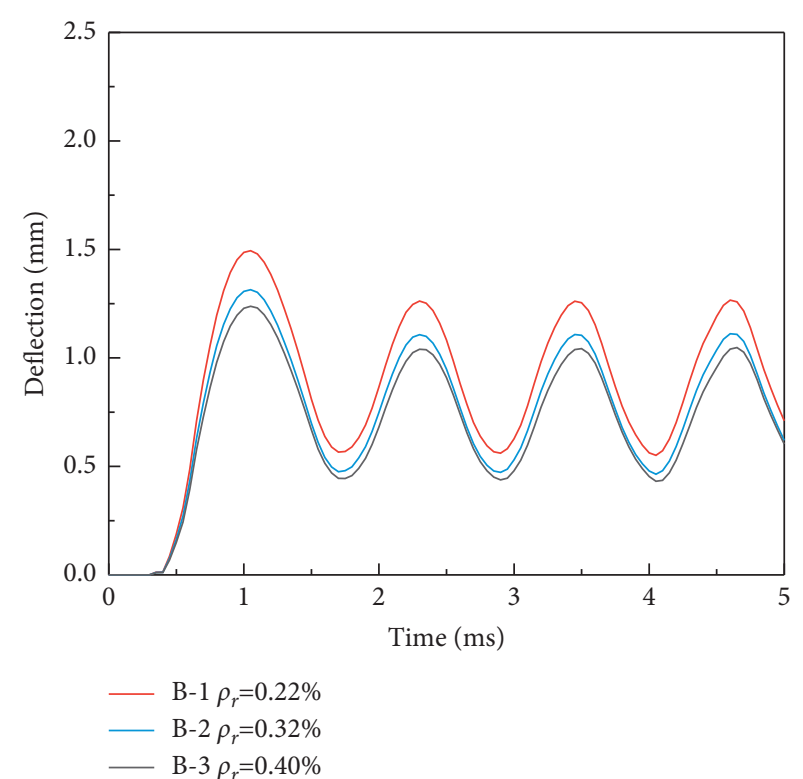

(b)

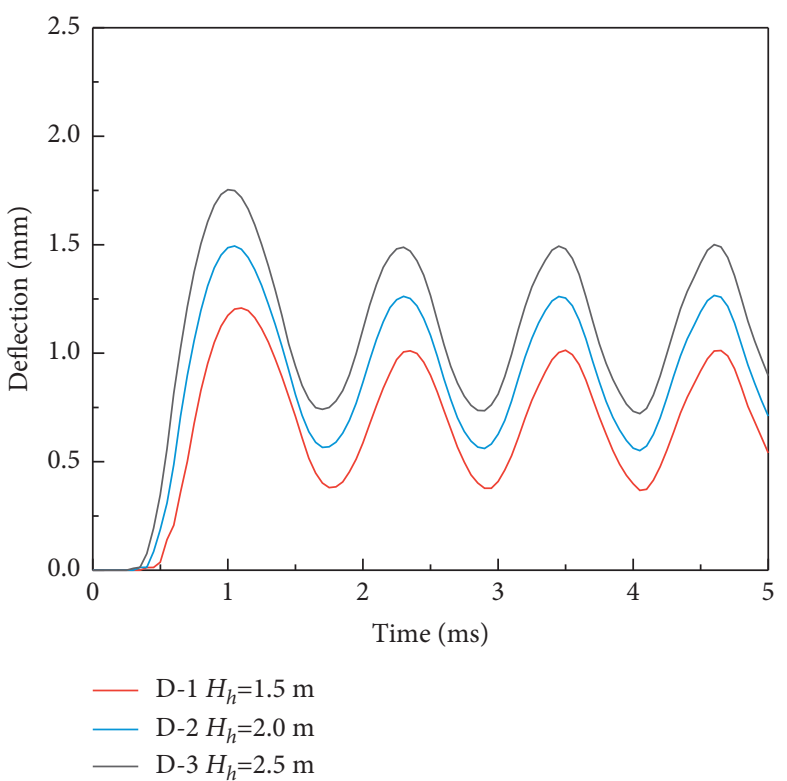

(d)

FIgURE 8: Time history curves of constrained force under the first impact.

residual deflection of RC slab, and the residual deflections of all cases are distributed from $0.4 \mathrm{~mm}$ to $1.2 \mathrm{~mm}$. From the simulation results, the increase of slab thickness will enhance the stiffness of the specimen and improve the impact resistance of the RC slab. However, the peak deflection of A-2 is larger than that of A-1, which is not consistent with the actual situation. The main reason for this phenomenon may be that the three specimens in group A must impact at the reinforcement mesh in the slab to exclude the interference of the impact point and reinforcement ratio of the study factors, which makes the drop hammer in A-2 not impact at the geometric center of the RC slab.
With the increase of reinforcement ratio, the impact resistance increases only slightly, which may be because the increase of reinforcement ratio enhances the flexural capacity of the specimen, and the plastic failure zone can be reduced under the same impact energy. However, compared to the enhanced stiffness, it is not as effective in improving the impact resistance performance. When the impact position changes, the peak deflection and residual deflection of C-3 are much larger than the other two cases. When the impact point is located at the reinforcement mesh, the hindering and restraining effect of the reinforcement is weaker, so the vibration response of the specimen is more obvious. With the growth of the initial 

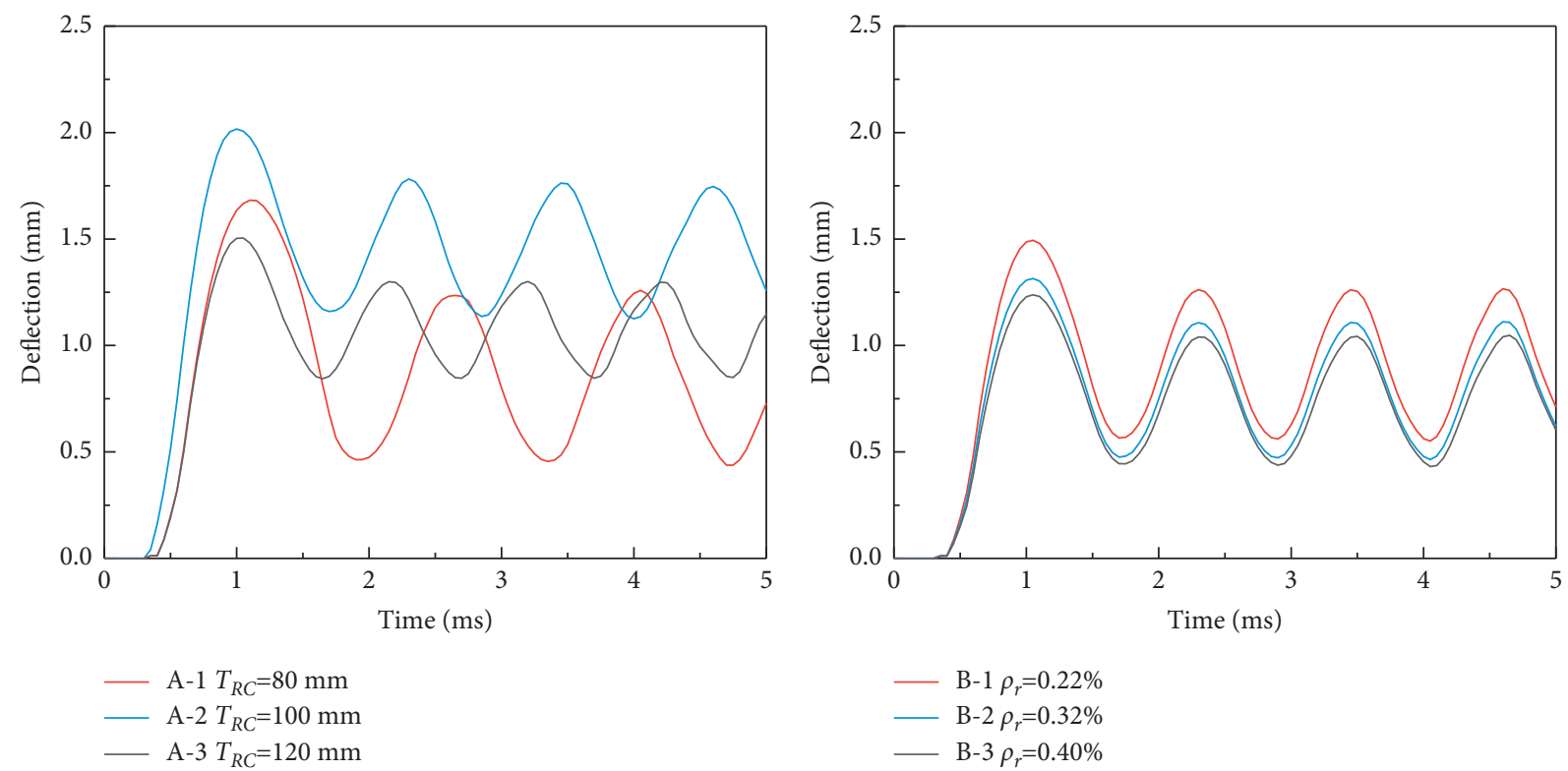

(a)

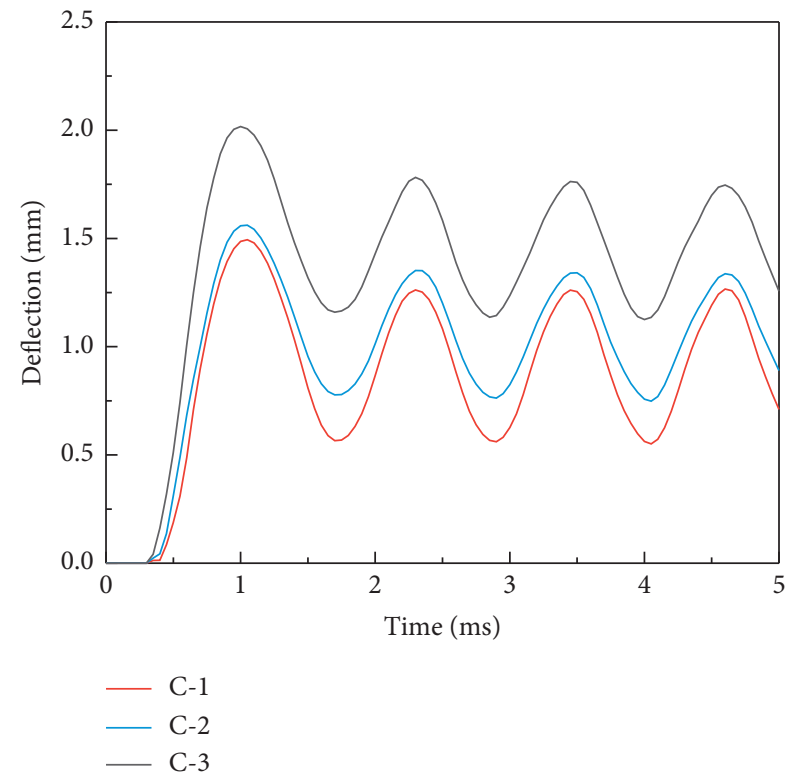

(c)

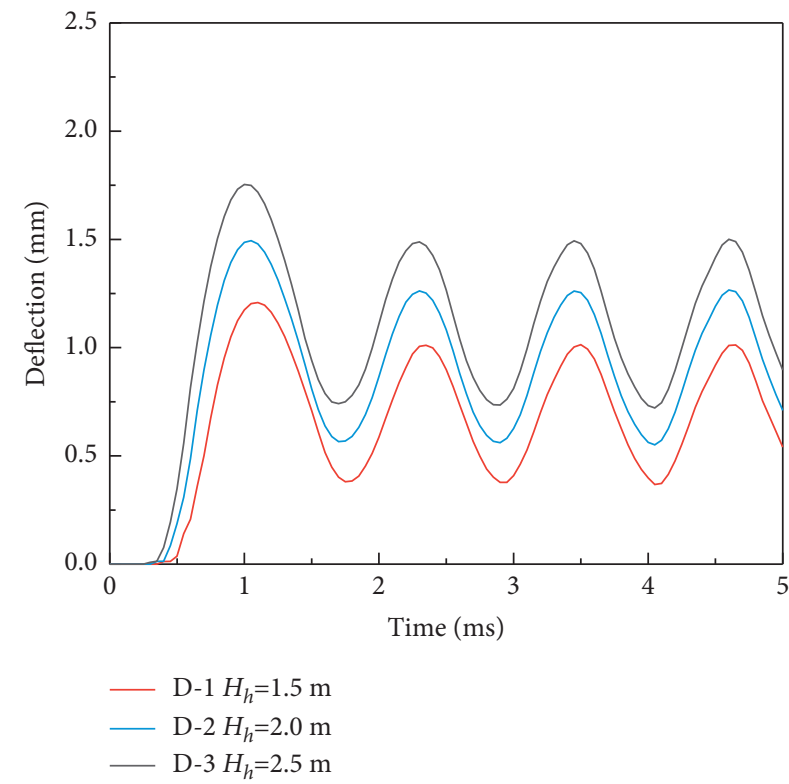

(d)

Figure 9: Time history curves of deflection of RC slab under the first impact.

height of the drop hammer, the peak and residual deflection of the RC slab grow significantly, which is the same pattern as that presented by the damage state of group $D$ in the test.

The deflection time history curves of the RC slab center under the second impact load are shown in Figure 10. In the same group, the curve with the change of parameters presents the same pattern as that of the first impact. The distinction with the first impact is that the vibration period becomes shorter. Besides, as shown in Figure 11, the increment of deflection (difference between the peak deflection and initial value) is smaller than that of the first impact. It may be because of the formation of damage area inside the specimen under the first impact load, which hinders the dynamic response.

4.5. Vertical Stress of RC Slab. Figure 12 shows the vertical (impact direction) stress cloud for the RC slab under the first impact load. There is a certain impact compressive stress at the contact between the drop hammer and the RC slab, which attenuates and diffuses outward to a half thickness of the slab.

The peak vertical compressive stresses in group A are 254.2 $\mathrm{MPa}, 431.8 \mathrm{MPa}, 774 \mathrm{MPa}$, indicating that the vertical impact compressive stress grows significantly with the 

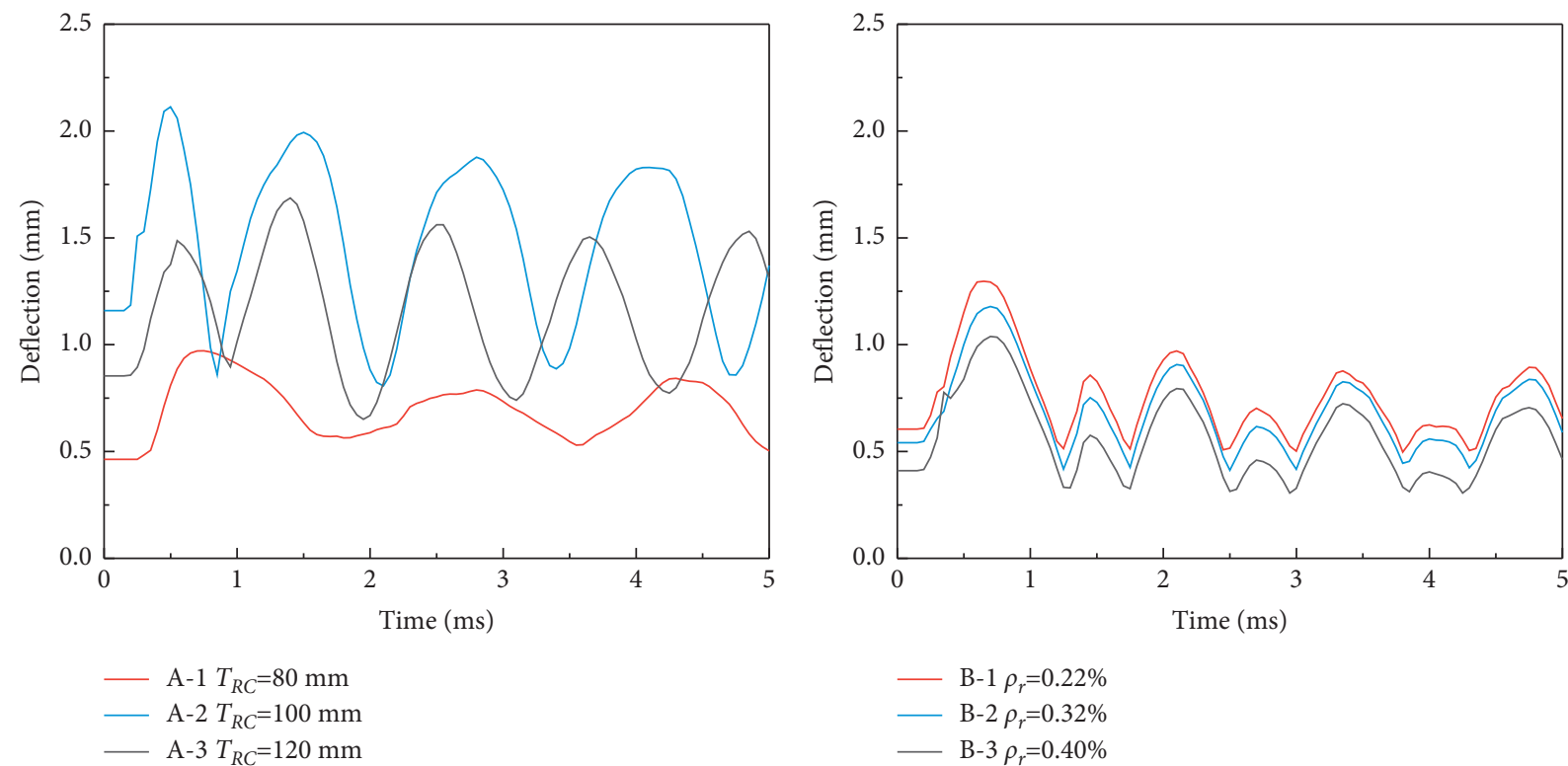

(a)

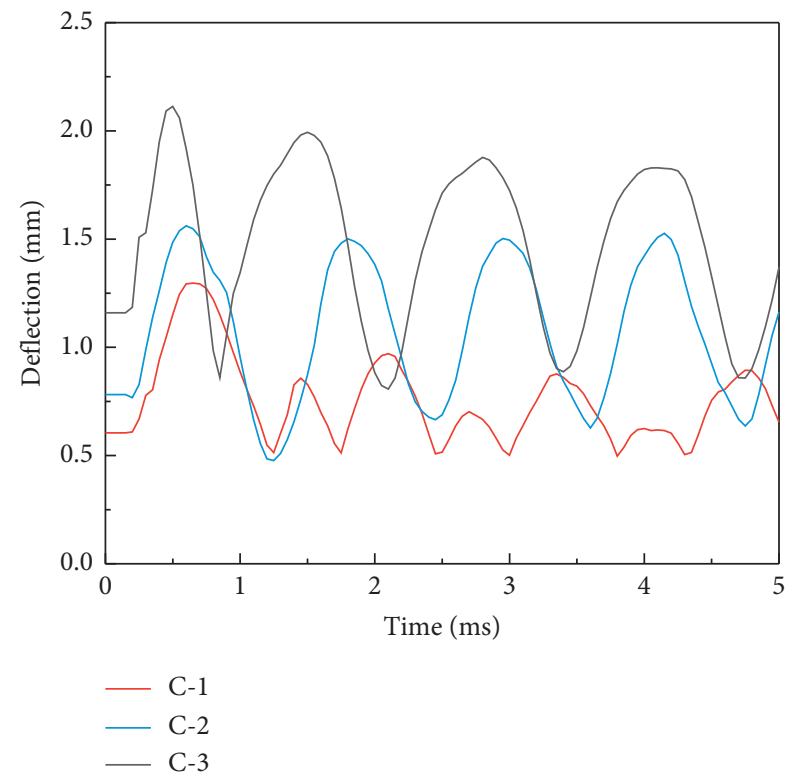

(c)

(b)

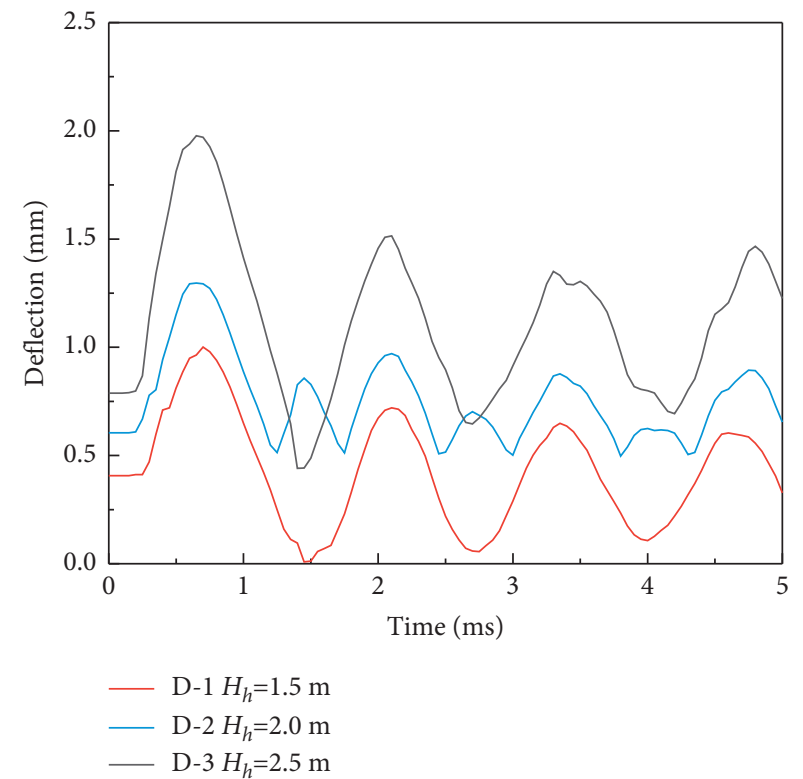

(d)

FIgUrE 10: Time history curves of deflection of RC slab under the second impact.

increase of slab thickness, which again proves that increasing the slab thickness can effectively improve the stiffness of the specimen. For B-1 3, the peak vertical compressive stresses are $259.5 \mathrm{MPa}$, $352.6 \mathrm{MPa}$, and $491.3 \mathrm{MPa}$, indicating that the vertical impact compressive stress increases steadily with the increase of reinforcement ratio. For C-1 3, the peak vertical compressive stresses are $259.5 \mathrm{MPa}, 269.3 \mathrm{MPa}$, and $431.8 \mathrm{MPa}$, respectively. The magnitudes of the vertical compressive stresses in C-1 and C-2 are close, while that of
C-3 is significantly greater, which is similar to the pattern presented by the deflection and restraint curves, indicating that the response of the RC slab is more violent and more prone to damage when the drop hammer hits the reinforcement mesh. For D-1 3, the peak vertical compressive stresses are 174.5 MPa, 259.5 MPa, and $316.8 \mathrm{MPa}$. Although the compressive stress increases with the increase of the drop hammer height, the enhancement is not significant compared with increasing the slab thickness. 

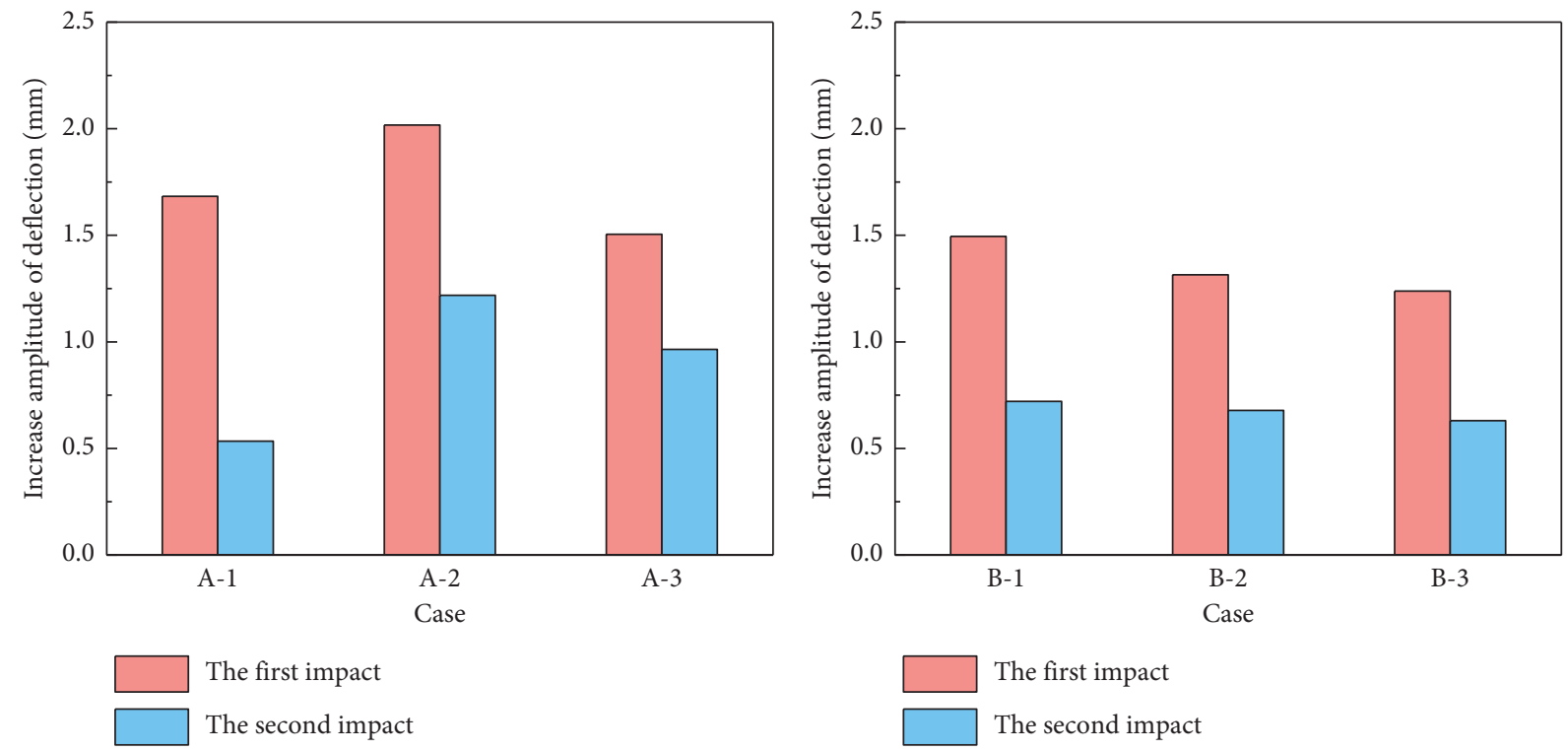

(a)

(b)
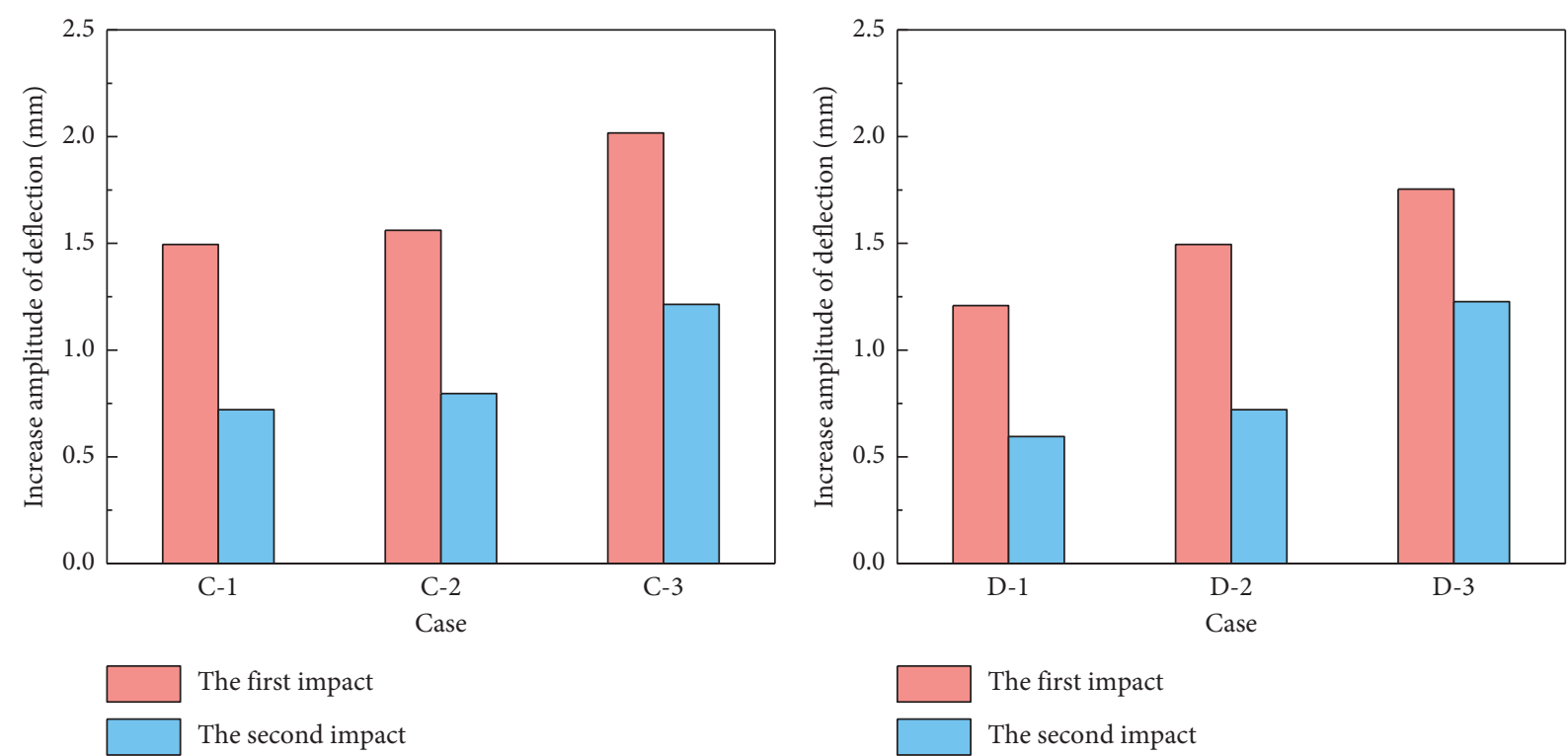

(c)

(d)

Figure 11: Comparison of deflection's increase amplitude by two impact loads. 


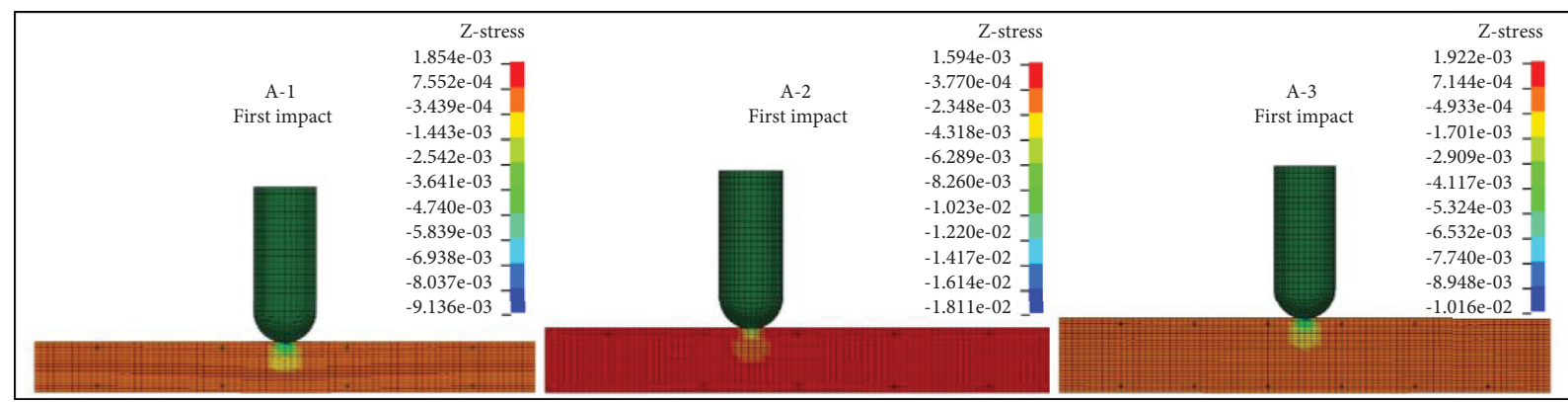

(a)

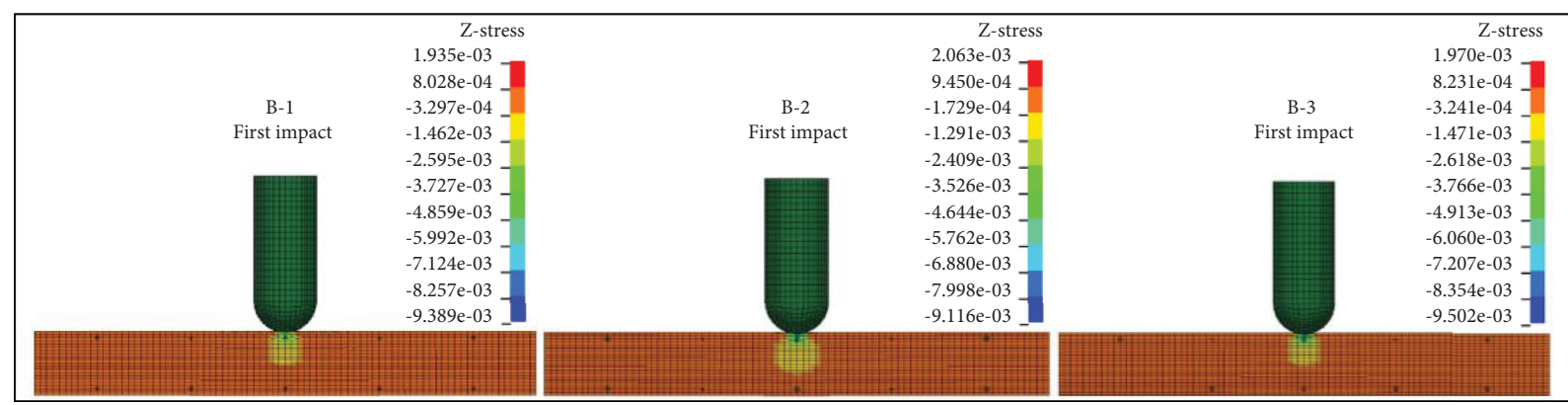

(b)

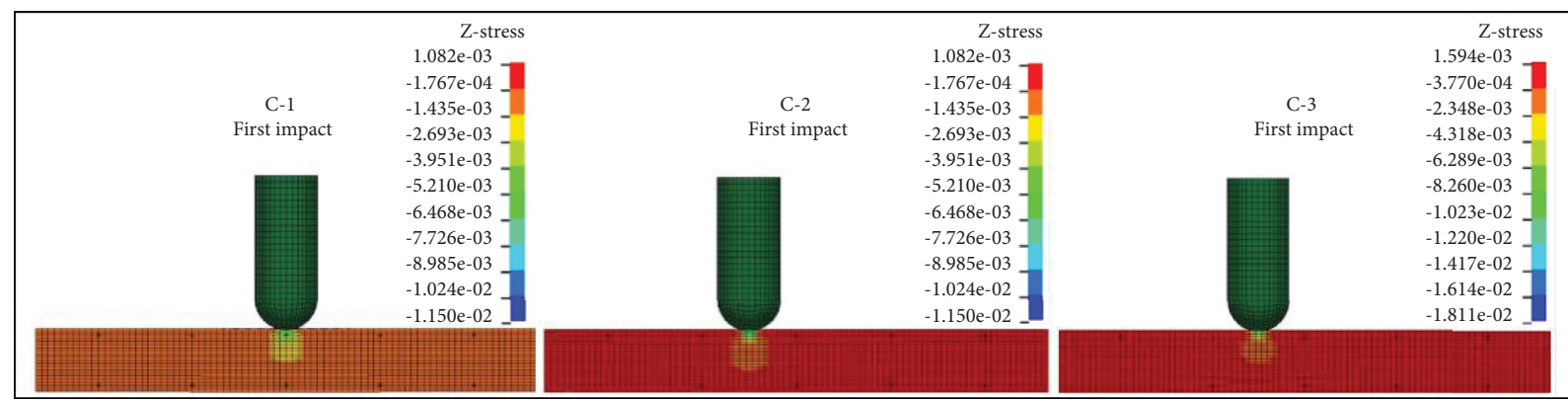

(c)

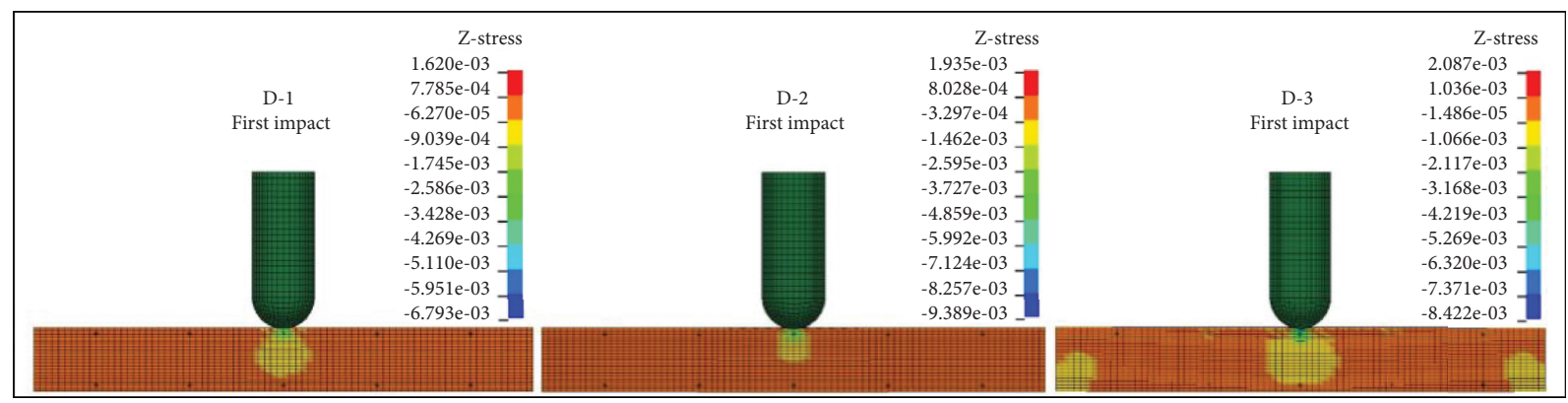

(d)

Figure 12: Vertical stress cloud for the RC slab under the first impact.

\section{Conclusions}

This paper presents an experimental and numerical simulation study of the dynamic response of RC slab under impact loading. The effects of four factors, such as slab thickness, reinforcement ratio, impact point location, and drop hammer height on the dynamic response of the RC slab under impact loading are investigated, and the differences of dynamic response under two continuous impact loads were compared. Additionally, the impact force, surface damage state, and slab center deflection under the two impact loads are compared. The main conclusions are as follows:

(1) As the thickness of the RC slab increases, the peak impact force increases, and the maximum value of the constrained force and vertical stress increases. When the thickness is $120 \mathrm{~mm}$, the damage of the slab surface is the smallest and the peak deflection of the slab is the smallest. In addition, with the height of the drop hammer, the impact force, peak deflection, 
constrained force, and maximum vertical stress increase. It indicates that increasing the slab thickness can enhance the impact resistance of the RC slabs, and the increase of impact energy intensifies the dynamic response of the slab.

(2) When the reinforcement ratio of the RC slab is in the range of $0.22 \% \sim 0.40 \%$, the peak deflection decreases slightly with the increase of the reinforcement ratio while the impact force and constrained force are less affected. When the impact point is located on the concrete at the reinforcement mesh, the deflection, constrained force, and vertical stress are larger than when impacting a single reinforcement (C-2) and reinforcement intersection (C-1). It is shown that upgrading the reinforcement ratio in this range can improve the impact resistance of the RC slabs slightly. Besides, the concrete at the reinforcement mesh of the RC slab is the weak area, and the dynamic response of the slab is stronger when it is impacted.

(3) After the second impact, the cracks on the concrete surface will continue to expand and be accompanied by the generation of new cracks. However, the peak impact force and the peak deflection under the second impact load are smaller than those of the first impact load. The reason for this phenomenon could be that the first impact load produces a local damage inside the concrete, which weakens the propagation of vibrations.

\section{Data Availability}

The data used to support the findings of this study are available from the corresponding author upon request.

\section{Conflicts of Interest}

The authors declare no potential conflicts of interest with respect to the research, authorship, and/or publication of this article.

\section{Acknowledgments}

This work was supported by the National Natural Science Foundation of China (Grant no. 51874118), the Fundamental Research Funds for the Central Universities (Grant no. B200203088), and Postgraduate Research \& Practice Innovation Program of Jiangsu Province (Grant no. KYCX20_0443).

\section{References}

[1] J. W. Tedesco, J. C. Powell, C. A. Ross, and M. L. Hughes, "A strain-rate-dependent concrete material model for ADINA," Computers \& Structures, vol. 64, no. 5-6, pp. 1053-1067, 1997.

[2] I. E. Shkolnik, "Influence of high strain rates on stress-strain relationship, strength and elastic modulus of concrete," Cement and Concrete Composites, vol. 30, no. 10, pp. 1000-1012, 2008.
[3] M. Z. Afifi, H. M. Mohamed, and B. Benmokrane, "Theoretical stress-strain model for circular concrete columns confined by GFRP spirals and hoops," Engineering Structures, vol. 102, no. 1, pp. 202-213, 2015.

[4] W. Riedel, K. Thoma, and S. Hiermaier, "Penetration of reinforced concrete by BETA-B-500 numerical analysis using a new macroscopic concrete model for hydrocodes," in Proceeding of the 9th International Symposium On the Effects OfMunitions With Structures, pp. 1-8, Berlin, Germany, 1999.

[5] M. Polanco-Loria, O. S. Hopperstad, T. Berstad, and T. Børvik, "Numerical predictions of ballistic limits for concrete slabs using a modified version of the HJC concrete model," International Journal of Impact Engineering, vol. 35, no. 5, pp. 290-303, 2008.

[6] Y. Liu, A. Ma, and F. Huang, "Numerical simulations of oblique-angle penetration by deformable projectiles into concrete targets," International Journal of Impact Engineering, vol. 36, no. 3, pp. 438-446, 2009.

[7] Z. Tu and Y. Lu, "Modifications of RHT material model for improved numerical simulation of dynamic response of concrete," International Journal of Impact Engineering, vol. 37, no. 10, pp. 1072-1082, 2010.

[8] J. Huo, Y. He, and B. Chen, "Experimental study on impact behavior of concrete-filled steel tubes at elevated temperatures up to 800," Materials and Structures, vol. 47, no. 1, pp. 263-283, 2014.

[9] A. L. Rosa, R. C. Yu, G. Ruiz, L. Saucedo, and J. L. A. O. Sousa, "A loading rate dependent cohesive model for concrete fracture," Engineering Fracture Mechanics, vol. 82, no. 5, pp. 195-208, 2012.

[10] K. Micallef, J. Sagaseta, and M. Fernández Ruiz, “Assessing punching shear failure in reinforced concrete flat slabs subjected to localised impact loading," International Journal of Impact Engineering, vol. 71, pp. 17-33, 2014.

[11] A. Q. Bhatti and N. Kishi, "Impact response of RC rock-shed girder with sand cushion under falling load," Nuclear Engineering and Design, vol. 240, no. 10, pp. 2626-2632, 2010.

[12] A. Özgür, E. Kantar, and M. C. Yilmaz, "Low velocity impact behavior of RC slabs with different support types," Construction and Building Materials, vol. 93, pp. 1078-1088, 2015.

[13] V. Kumar, M. A. Iqbal, and A. K. Mittal, "Impact resistance of prestressed and reinforced concrete slabs under falling weight indenter," Procedia Structural Integrity, vol. 6, pp. 95-100, 2017.

[14] Y. Li, Z. Chen, X. Ren, R. Tao, R. Gao, and D. Fang, "Experimental and numerical study on damage mode of RC slabs under combined blast and fragment loading," International Journal of Impact Engineering, vol. 142, Article ID 103579, 2020.

[15] S. Yao, D. Zhang, X. Chen, F. Lu, and W. Wang, "Experimental and numerical study on the dynamic response of RC slabs under blast loading," Engineering Failure Analysis, vol. 66, pp. 120-129, 2016.

[16] R. Wang, L.-H. Han, and Z. Tao, "Behavior of FRP-concretesteel double skin tubular members under lateral impact: experimental study," Thin-Walled Structures, vol. 95, no. 5, pp. 363-373, 2015.

[17] Y. Sha and H. Hao, "Laboratory tests and numerical simulations of CFRP strengthened RC pier subjected to barge impact load," International Journal of Structural Stability and Dynamics, vol. 15, no. 2, pp. 1-33, 2015.

[18] H. Soltani, A. Khaloo, and H. Sadraie, "Dynamic performance enhancement of RC slabs by steel fibers vs. externally bonded 
GFRP sheets under impact loading," Engineering Structures, vol. 213, Article ID 110539, 2020.

[19] K. Daneshvar, M. J. Moradi, K. Ahmadi, and H. Hajiloo, "Strengthening of corroded reinforced concrete slabs under multi-impact loading: experimental results and numerical analysis," Construction and Building Materials, vol. 284, Article ID 122650, 2021.

[20] M. Colombo, P. Martinelli, A. Arano et al., "Experimental investigation on the structural response of RC slabs subjected to combined fire and blast," Structure, vol. 31, pp. 1017-1030, 2021.

[21] J. Ozbolt and A. Sharma, "Numerical simulation of reinforced concrete beams with different shear reinforcements under dynamic impact loads," International Journal of Impact Engineering, vol. 38, no. 12, pp. 940-950, 2011.

[22] J. Y. Lee, M. H. Kim, K. H. Min, and Y. S. Yoon, "Analysis of behaviors of concrete strengthened with FRP sheets and steel fibers under low-velocity impact loading," Journal of the Korea Institute for Structural Maintenance and Inspection, vol. 15, no. 4, pp. 155-164, 2011.

[23] J. Y. Lee, H. O. Shin, K. H. Min, and Y. S. Yoon, “Analytical evaluation of high velocity impact resistance of two-way RC slab reinforced with steel fiber and FRP sheet," Journal of the Korea Institute for Structural Maintenance and Inspection, vol. 17, no. 3, pp. 1-9, 2013.

[24] W. Zhao and J. Qian, "Dynamic response and shear demand of reinforced concrete beams subjected to impact loading," International Journal of Structural Stability and Dynamics, vol. 15, no. 6, pp. 159-167, 2019.

[25] Y. Wang, X. Qian, J. Y. R. Liew, and M.-H. Zhang, "Impact of cement composite filled steel tubes: an experimental, numerical and theoretical treatise," Thin-Walled Structures, vol. 87, no. 6, pp. 76-88, 2015.

[26] P. Yan, J. Zhang, Q. Fang, and Y. Zhang, "Numerical simulation of the effects of falling rock's shape and impact pose on impact force and response of RC slabs," Construction and Building Materials, vol. 160, pp. 497-504, 2018.

[27] D. Z. Yankelevsky, Y. S. Karinski, A. Brodsky, and V. R. Feldguna, "Dynamic punching shear of impacting RC flat slabs with drop panels," Engineering Failure Analysis, vol. 129, Article ID 105682, 2021.

[28] R. Castedo, A. P. Santos, A. Alañón, and C. Reifarth, "Numerical study and experimental tests on full-scale RC slabs under close-in explosions," Engineering Structures, vol. 231, Article ID 111774, 2021.

[29] W. J. Yi, D. B. Zhao, and S. K. Kunnath, "Simplified approach for assessing shear resistance of reinforced concrete beams under impact loads," ACI Structural Journal, vol. 113, no. 4, pp. 15-28, 2016.

[30] T. Liu and Y. Xiao, "Impact behavior of CFRP-strip wrapped RC beams without stirrups," ASCE Journal of Composites for Construction, vol. 21, no. 5, pp. 1-14, 2017.

[31] S. Xiao, W. Cao, and H. Pan, "Experimental study on mechanical behavior of reinforced concrete beams at different loading rates," Journal of Building Structures, vol. 33, no. 12, pp. 142-146, 2012.

[32] D. Wang, H.-N. Li, and G. Li, "Experimental tests on reinforced concrete columns under multi-dimensional dynamic loadings," Construction and Building Materials, vol. 47, no. 20, pp. 1167-1181, 2013.

[33] Z. Majeed, N. Lam, and E. F. Gad, "Predictions of localised damage to concrete caused by a low-velocity impact," International Journal of Impact Engineering, vol. 149, Article ID 103799, 2020.
[34] H. Hao, T. T. Tran, H. Li, T. M. Pham, and W. Chen, "On the accuracy, reliability and controllability of impact tests of RC beams," International Journal of Impact Engineering, vol. 157, Article ID 103979, 2021. 